\title{
Effects of site-city interaction and polarization of the incident S-wave on the transfer function and fundamental frequency of structures
}

\author{
Neeraj Kumar ${ }^{1}$ J. P. Narayan ${ }^{1}$
}

Received: 27 December 2016 / Accepted: 16 July 2019 / Published online: 23 July 2019

(c) The Author(s) 2019

\begin{abstract}
The variation of $2 \mathrm{D}$ fundamental frequency of stand-alone structure on rock $\left(F_{02 \mathrm{D}}^{\mathrm{S}}\right)$ and in a basin $\left(F_{02 \mathrm{D}}^{\mathrm{BS}}\right)$ with the polarization of the incident $\mathrm{S}$-wave is presented. This paper also presents the role of city density and polarization of the exciting S-wave in the site-city interaction effects on the response of structures in a city as well as free-field motion. The seismic responses of the various considered basin and site-city models are computed using $\mathrm{SH}$-wave and P-SV-wave finite-difference programs. A considerable decrease in the value of $F_{02 \mathrm{D}}^{\mathrm{S}}$ of stand-alone structure on rock is obtained with the increase in shape ratio for the SV-wave but not for the SH-wave, as compared to the 1D fundamental frequency of structure $\left(F_{01 \mathrm{D}}^{\mathrm{S}}\right)$. However, a considerable decrease in the value of $F_{02 \mathrm{D}}^{\mathrm{BS}}$ of a stand-alone structure in basin under double resonance condition is obtained for the $\mathrm{SH}$-wave and not for the SV-wave. The spectral amplification factor at the top of a structure at $F_{02 \mathrm{D}}^{\mathrm{BS}}$ of structure is larger for the SV-wave as compared to the SH-wave. A splitting of the bandwidth of the fundamental mode of vibration of structure and very large reduction in spectral amplification factor at $F_{02 \mathrm{D}}^{\mathrm{BS}}$ of structure is obtained due to the site-city interaction effects under double resonance condition for both the S-wave polarizations. Further, an increase in these inferred effects with an increase in city density and number of structures in a city with a constant city density is obtained. This finding raises the question concerning the validity of ground-motion prediction using soil-structure interaction for the design of structures in an urban environment. Further, the decrease in spectral amplification factor at $F_{02 \mathrm{D}}^{\mathrm{BS}}$ of structure due to the site-city interaction effects is larger in the case of SV-wave as compared to $\mathrm{SH}$-wave. Furthermore, a considerable site-city interaction effects on free-field motion is obtained.
\end{abstract}

Keywords Fundamental frequency of basin and structure - Site-city interaction effects . $\mathrm{S}$-wave polarization $\cdot$ City density $\cdot$ Double resonance

J. P. Narayan jaypnfeq@iitr.ac.in

Neeraj Kumar neerajlohchab018@gmail.com

1 Department of Earthquake Engineering, Indian Institute of Technology Roorkee, Roorkee, India 


\section{Introduction}

The explanation of behaviour of buildings during an earthquake is a great challenge for researchers because of the complex soil-structure interaction phenomenon. The past studies have revealed that the kinematic soil-structure interaction largely affects the seismic response of structures (Housner 1954; Wong and Trifunac 1975). On the other hand, during earthquake, the wave field generation by building vibration in the underlying sediment is due to the inertial structure-soil interaction phenomenon (Bard et al. 2005). The mass and stiffness play an important role in the dynamic response of a building, and it also modifies the nearby site response around structure (Cornou, et al. 2004; Gallipoli et al. 2004). The Millikan Library Building test at California Institute of Technology by Jennings (1970), the analysis of records caused by vibration in the highrise buildings in Los Angles in response to shock wave of Columbia space shuttle on its return (Kanamori et al. 1991), Volvi experiment (Gueguen and Bard 2005) and analysis of records of Lamont network during the terrorist attack on World Trade Centre by Kim et al. (2001) are the examples of studies associated with effects of inertial structure-soil interaction on the structure and seismic ground motion (Stewart et al. 1999; Guéguen et al. 2002; Gueguen 2008; Chandra and Guéguen 2017).

The site-city interaction on a global scale affects both the seismic response of structures of the city as well as free-field ground motion within and outside the city (Wirgin 1995; Wirgin and Bard 1996; Gueguen et al. 2000; Kham et al. 2006; Sahar et al. 2015; Kumar and Narayan 2018). Most of the past theoretical studies on the site-city interaction effects were carried out under double resonance condition, where resonance frequency of the structure matches with that of the 1D basin (Chavez-Garcia and Cardenas-Soto 2002; Gueguen 2008; Semblat et al. 2008). The extensive literature review on the site-city interaction effects reflects that the 2D or 3D resonance frequency of the building block models (generally used in place of real structure) is neglected. The 2D fundamental resonance frequency of a structure may differ with the 1D fundamental frequency of the same structure predicted using certain empirical relationship. For example, Kham et al. (2006) studied site-city interaction effects by exciting regular and irregular cities with SH-wave in a basin, whose nature was 1D. Similarly, Semblat et al. (2008) simulated the SH-wave responses of regular, irregular and realistic cities situated in the Nice basin, whose nature is again 1D.

Similarly, nobody has paid attention whether resonance frequency of the building block model depends on the polarization of the incident S-wave. However, there are few studies on the prediction of 2D fundamental frequency of basin and its dependency on the polarization of the incident $\mathrm{S}$-wave, shape of basin and shape ratio of basin, particularly in case of large shape ratio (Roten et al. 2006; Meza-Fajardo et al. 2016; Zhu and Thambiratnam 2016). The shape ratio of basin in this paper is defined as $D / W$, where ' $D$ ' is the depth of basin and ' $W$ ' is the half-width of basin. Bard and Bouchon (1985) have given empirical relations to predict the 2D fundamental resonance frequency of the basin $\left(F_{02 \mathrm{D}}^{\mathrm{B}}\right)$ as well as have reported that $F_{02 \mathrm{D}}^{\mathrm{B}}$ of a basin is larger than the lowest 1D resonance frequency of the same basin $\left(F_{01 \mathrm{D}}^{\mathrm{B}}\right)$, and the difference between the 1D and 2D fundamental frequencies increases with the increase in shape ratio of basin. Paolucci (1999) have simulated the responses of various 2D and 3D basins and have given empirical relations to predict the fundamental frequency of elliptical-shaped closed basins. They have also reported a considerable difference between the 2D fundamental frequency of a basin for the SH-wave and the SV-wave. 
The day-by-day increase in population of most of the Indian cities mainly due to migration, high birth rate and economical factors is pressurizing the builders to construct structures even at the vulnerable sites like near the river beds, sediment-filled lakes and ponds, etc. Most of the earthquake engineers are using 1D fundamental frequency of sediment deposit in basin in designing earthquake-resistant structures. In order to fulfil the abovementioned research gaps and social unawareness, the research work carried out for this paper is divided into three subsections. The first subsection of this paper presents the variation of $2 \mathrm{D}$ fundamental frequency of structure and basin with shape ratio $(\mathrm{H} / \mathrm{W})$ and the polarization of the exciting incident S-wave. The effects of 1D fundamental frequency of basin on the fundamental frequency of the structure as well as its response is documented in the second subsection. In the third subsection, the effects of site-city interaction on the variation of $2 \mathrm{D}$ fundamental frequency of structure and corresponding spectral amplification factor as well as free-field motion due to change of polarization of the incident S-wave and the city density are given. The SH-wave and SV-wave responses of the various considered basins, structures and site-city models are simulated using recently developed fourthorder viscoelastic staggered-grid finite-difference SH-wave (Narayan and Kumar 2013) and P-SV-wave (Narayan and Kumar 2014) programs.

\section{Salient features of used FD algorithms}

A frequency-dependent damping in the time-domain simulations of responses of basins, structures and site-city models is essential for accurate prediction of fundamental frequency of 2D basin and structure, SAF and SCI effects on the characteristics of free-field ground motion (Narayan and Sahar 2014). A fourth-order accurate SH- and P-SV-wave viscoelastic FD programs have been used for the simulation of responses of the considered various models (Narayan and Kumar 2013, 2014). The frequency-dependent damping in the FD simulations is incorporated based on the GMB-EK rheological model (Emmerich and Korn 1987). In the stress-strain relations, material-independent anelastic functions have been used since it is beneficial in case of material discontinuities in the model (Kristeck and Moczo 2003). The details of computations of the unrelaxed moduli $\left(M_{\mathrm{U}}\right)$, anelastic coefficients $\left(Y_{1}\right)$ and anelastic functions $\left(\chi_{1}\right)$ are given in (Narayan and Kumar 2013, 2014). The effective values of the unrelaxed Lame's parameters and density at the desired locations in the staggered grid are obtained using the harmonic and arithmetic means, respectively (Moczo et al. 2002). Free-surface boundary condition is applied using the improved vacuum formulation (Zeng et al. 2012). The sponge-absorbing boundary condition is implemented on the model edges to avoid the edge reflections (Israeli and Orszag 1981).

\section{Fundamental frequency of 2D structures and basins}

\subsection{Parameters of basins and building block models}

In order to predict the two-dimensional (2D) fundamental frequency of structure $\left(F_{02 \mathrm{D}}^{S}\right)$, first, dependency of fundamental frequency of the $2 \mathrm{D}$ closed rectangular basins $\left(F_{02 \mathrm{D}}^{\mathrm{B}}\right)$ on the shape ratio is studied in detail taking the same dimensions and parameters as that of the considered structures. The quantification of variation of fundamental frequency of 

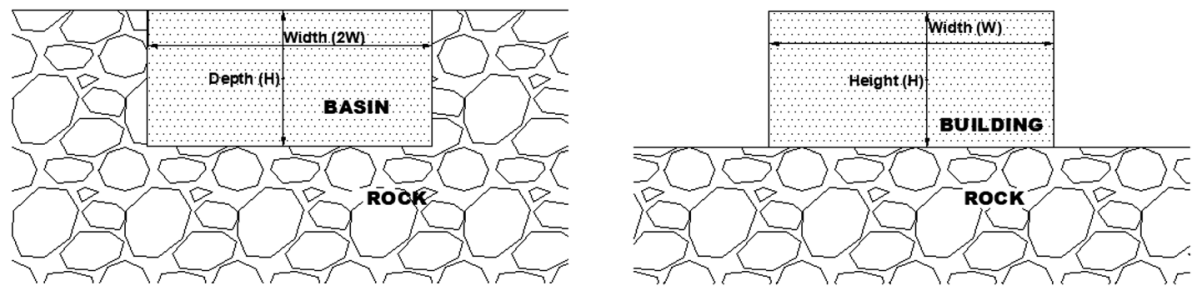

Fig. 1 Sketches for the rectangular basin model (left) and building block model (right)

Table 1 Seismic parameters for the various material components of the model

\begin{tabular}{lccccccccc}
\hline Materials & $V_{\mathrm{S}}(\mathrm{m} / \mathrm{s})$ & $V_{\mathrm{P}}(\mathrm{m} / \mathrm{s})$ & $Q_{\mathrm{S}}$ & $Q_{\mathrm{P}}$ & Density $\left(\mathrm{kg} / \mathrm{m}^{3}\right)$ & \multicolumn{3}{c}{ Unrelaxed moduli $(\mathrm{GPa})$} \\
\cline { 7 - 10 } & & & & & & $\mu_{\mathrm{u}}$ & \multicolumn{1}{c}{$K_{\mathrm{u}}$} & $\lambda_{\mathrm{u}}$ \\
\hline Structure & 120 & 204 & 10 & 17 & 350 & 0.0064 & 0.0168 & 0.0039 \\
Basin & 350 & 595 & 35 & 59.5 & 1800 & 0.2628 & 0.7377 & 0.2121 \\
Rock & 1800 & 4500 & 180 & 450 & 2500 & 8.2104 & 50.899 & 34.478 \\
\hline
\end{tabular}

structure and basin on the polarization of the exciting S-wave is an important study that needs special attention in earthquake engineering. The numerically computed $F_{02 \mathrm{D}}^{\mathrm{B}}$ of $2 \mathrm{D}$ rectangular basins are verified using the empirical relationships proposed by Bard and Bouchon (1985) for the SH-wave and SV-wave. This validation seems essential to built the confidence since there is no such relationship available to predict the 2D fundamental frequency of a structure for the $\mathrm{SH}$-wave $\left(\mathrm{SHF}_{02 \mathrm{D}}^{S}\right)$ and $\mathrm{SV}$-wave $\left(\mathrm{SVF}_{02 \mathrm{D}}^{S}\right)$. The heights of the considered 10- and 20-storey structures are $30 \mathrm{~m}$ and $60 \mathrm{~m}$, respectively. The structure is incorporated in the FD grid using a homogeneous building block model (Bard et al. 2005; Sahar et al. 2015; Sahar and Narayan 2016). Figure 1 depicts the rectangular basin (left) and the building block model (right), respectively. The details of finding the time period of the considered buildings as per IS:1893 code as well as fixing the same based on the output of the SAP-15 analysis and computation of other parameters are given in Sahar et al. (2015). The 1D fundamental frequency of building block model $\left(F_{01 \mathrm{D}}^{S}\right)$ for the 10- and 20-storey structures is obtained as $1.0 \mathrm{~Hz}$ and $0.5 \mathrm{~Hz}$, respectively. The $F_{01 \mathrm{D}}^{S}$ of building block model is used to compute the effective $S$-wave velocity for the building block model. The effective shear wave velocity obtained as $120 \mathrm{~m} / \mathrm{s}$ for the building block model is computed using a simple relation $V_{\mathrm{s}}=4 \mathrm{HF}_{0}$. The effective density of the building was obtained as $350 \mathrm{~kg} / \mathrm{m}^{3}$ using the length, height, thicknesses and densities of walls, slabs and beams (Sahar et al. 2015) and live load acting on the each floor of building.

The $\mathrm{P}$ - and $\mathrm{S}$-wave velocities and the quality factors at a reference frequency $\left(F_{\mathrm{R}}=1.0 \mathrm{~Hz}\right)$, densities and unrelaxed moduli for the building block model and rock are given in Table 1. The relaxation frequencies used were $0.02 \mathrm{~Hz}, 0.2 \mathrm{~Hz}, 2.0 \mathrm{~Hz}$ and $20 \mathrm{~Hz}$. The details of computation of unrelaxed moduli and anelastic coefficients for the SH- and P-SV-waves simulation are given in Narayan and Kumar $(2013,2014)$. The numerical model is discretized with the grid size of $3.0 \mathrm{~m}$ in the horizontal direction and $3.0 \mathrm{~m}$ in the vertical direction up to a depth of $165 \mathrm{~m}$ and $10 \mathrm{~m}$ thereafter. Further, the time step is taken as $0.0003 \mathrm{~s}$ to avoid the numerical instability of the explicit FD scheme. Absorbing boundaries are applied at the bottom and side edges to avoid the edge reflections. A plane 
SH- and SV-wave fronts are generated into the FD grid using various point sources along a horizontal line at a depth of $715 \mathrm{~m}$ using shear stress components $\sigma_{Y Z}$ in the SH-wave FD program and $\sigma_{X Z}$ in the P-SV FD program, respectively, in the form of Gabor wavelet. The mathematical form of the Gabor wavelet is given below

$$
S(t)=e^{-\alpha} \cdot \cos [\omega p(t-t s)+\phi]
$$

where $\alpha=\frac{\omega p(t-t s)^{2}}{\gamma}, f_{\mathrm{p}}$ is predominant frequency, $\Upsilon$ controls the oscillatory character, $t_{\mathrm{s}}$ controls the duration of wavelet and $\phi$ is the phase shift. Figure 2 shows the generated Gabor wavelet for $f_{\mathrm{p}}=2, \gamma=0.5, t_{\mathrm{s}}=1.5$ and $\phi=0$ and its spectra. The frequency bandwidth of the generated Gabor wavelet is $0-6.0 \mathrm{~Hz}$.

\subsection{Effects of polarization of $S$-wave on $F_{02 D}^{B}$ of basin}

The responses of various rectangular basins with the same parameters and dimensions as that of the considered structures are computed to validate the computed $F_{02 \mathrm{D}}^{\mathrm{B}}$ of basin for the SH-wave and SV-wave. Eight basin models, namely BM1, BM2, BM3, BM4, BM5, BM6, BM7 and BM8, are considered to compute the effects of shape ratio (D/W) of basin on the $2 \mathrm{D}$ fundamental frequency of basin for the $\mathrm{SH}$-wave $\left(\mathrm{SH} F_{02 \mathrm{D}}^{\mathrm{B}}\right)$ and for the $\mathrm{SV}$-wave $\left(\mathrm{SVF}_{02 \mathrm{D}}^{\mathrm{B}}\right)($ Table 2$)$. The parameters like depth $(D)$, width $(2 W)$ and $F_{01 \mathrm{D}}^{\mathrm{B}}$ of these models are also given in Table 2. Bard and Bouchon (1985) have given empirical relations to determine the fundamental frequency of rectangular basin for the SH-wave and SV-wave, as given below.

$$
\begin{gathered}
\mathrm{SH} F_{2 \mathrm{D}}^{\mathrm{B}}=F_{01 \mathrm{D}}^{B} \sqrt{\left[(2 m+1)^{2}+(n+1)^{2} \times h^{2} / w^{2}\right]} \\
\mathrm{SV} F_{02 \mathrm{D}}^{\mathrm{B}}=F_{01 \mathrm{D}}^{B} \sqrt{\left[1+(1.45 h / w)^{2}\right]}
\end{gathered}
$$

where $F_{01 \mathrm{D}}^{\mathrm{B}}$ is the 1D fundamental frequency, and ' $h$ ' and ' $w$ ' are, respectively, the depth and half-width of the rectangular basin. The order ' $m$ ' and ' $n$ ' represents the different modes of vertical and horizontal resonances, respectively. Bard and Bouchon (1985) also stated that the prediction of higher modes of vibrations of basin for the SV-wave is complicate for even a simple case of rectangular basin.

The SH- and SV-wave responses of all the BM1-BM8 basin models were computed at the centre of basins. A comparison of the SH- and SV-wave responses of the BM1-BM4 rectangular basin models is shown in Fig. 3. The analysis of Fig. 3 depicts that there is considerable effects of basin shape ratio and the $\mathrm{S}$-wave polarization on the basin response.
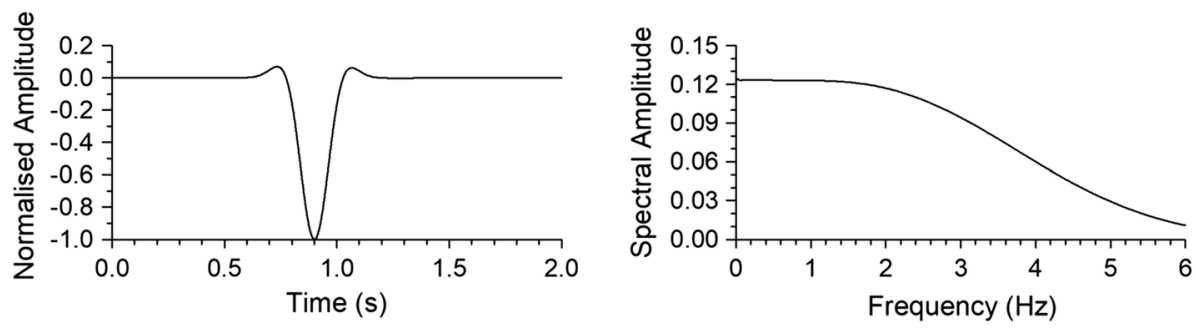

Fig. 2 Gabor wavelet in time domain and its spectra 


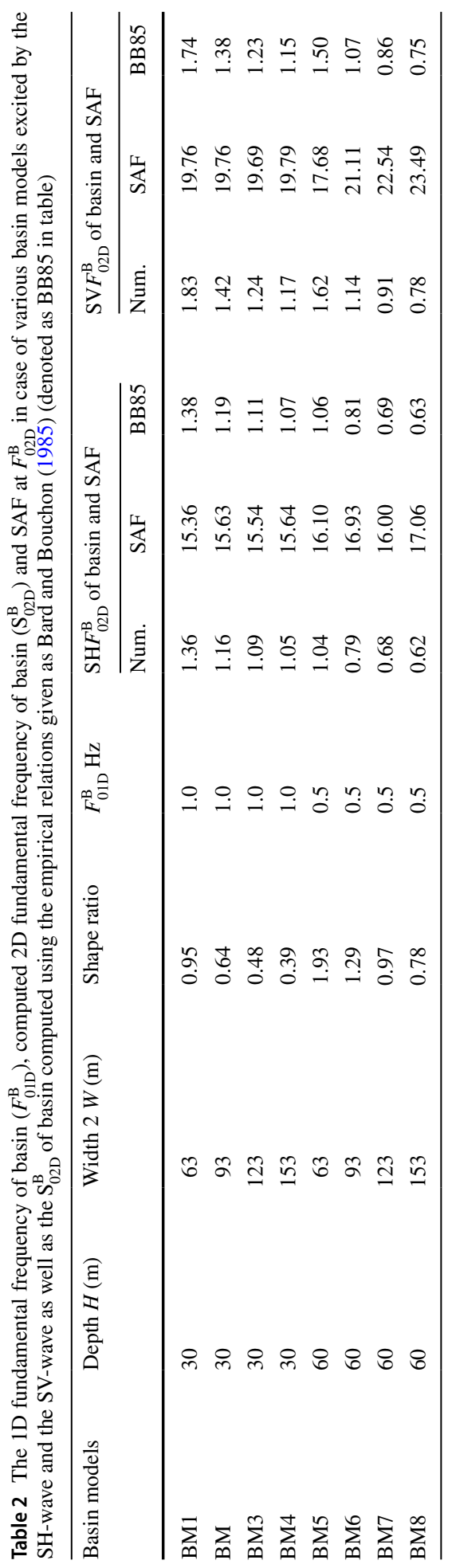




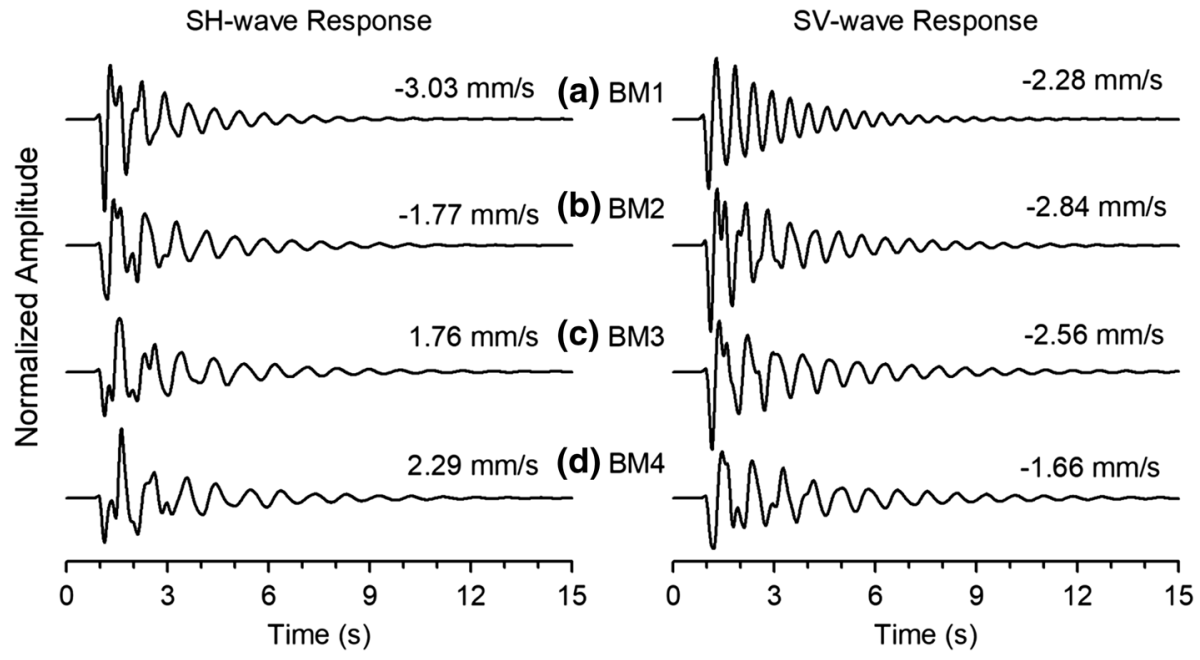

Fig. 3 a-d The SH-wave (left panel) and SV-wave (right panel) responses at the centre of the BM1-BM4 rectangular basin models, respectively (Table 3)

It is observed that as the width of basin increases the duration of ground motion increases in both the SH-wave and SV-wave responses. On an average, the largest amplitude in the respective basin is more in the $\mathrm{SH}$-wave responses, but the duration and number of cycles are more in the $\mathrm{SV}$-wave responses, although the $\mathrm{SH}$ - and $\mathrm{SV}$-wave responses are exactly the same on the exposed rock (result not shown here).

A comparison of spectral amplification factors (SAF) for the SH- and SV-waves at the centre of BM1-BM8 basin models is shown in Fig. 4a-h, respectively. The SAF is computed using the spectra of the SH- or SV-wave responses with and without basin in the model. The analytically obtained $F_{01 \mathrm{D}}^{\mathrm{B}}$ of BM1-BM8 basin models is also given in Table 2. Further, the computed SAF at $F_{01 \mathrm{D}}^{\mathrm{B}}$ is 6.15 for all the basin models using the relation $\frac{1}{1 / \mathrm{IC}+0.5 \pi \varepsilon}$ (where $I C$ is impedance contrast and ' $\varepsilon$ ' is damping). Now, the analysis of Fig. 4 and Table 2 depicts that both the $F_{02 \mathrm{D}}^{\mathrm{B}}$ of basin and the corresponding SAF are increasing with the decrease in basin shape ratio in both the cases of SH- and SV-wave responses. Further, $F_{02 \mathrm{D}}^{\mathrm{B}}$ of basin is larger than the corresponding $F_{01 \mathrm{D}}^{\mathrm{B}}$ of basin in both the cases of $\mathrm{SH}$ - and SV-wave responses. Table 2 also depicts that the $\mathrm{SV} F_{02 \mathrm{D}}^{\mathrm{B}}$ of basin is larger than the $\mathrm{SH} F_{02 \mathrm{D}}^{\mathrm{B}}$ of basin for a particular basin shape ratio. Similarly, the $\mathrm{SAF}$ at $\mathrm{SV} F_{02 \mathrm{D}}^{\mathrm{B}}$ of basin is larger than that at $\mathrm{SH} F_{02 \mathrm{D}}^{\mathrm{B}}$ of basin for the same shape ratio.

In order to validate the accuracy of the numerically computed $\mathrm{SH} F_{02 \mathrm{D}}^{\mathrm{B}}$ and $\mathrm{SVF} F_{02 \mathrm{D}}^{\mathrm{B}}$ as well as higher modes of vibrations of the considered basin models, a comparison of numerically computed different modes of vibrations of basins for the SH-waves with those computed using relationship proposed by Bard and Bouchon (1985) is given in Fig. 4 and Table 3. The different modes of vibrations of basin for the SH-wave corresponding to the different modes of vibrations in the vertical $(m)$ and horizontal $(n)$ directions are presented using the notation $F_{j}(m, n)$ in Table 3 . In this notation, ' $j=0,1,2,3,4,5 \ldots$ ' represents the modes of vibration of the overall basin, as shown in Fig. 4 . For example, $F_{0}$ is the fundamental mode, F1 is the first mode and so on. It may be concluded that the frequencies corresponding to different modes of vibrations of the $2 \mathrm{D}$ rectangular basin depend on the shape ratio. The analysis of Tables 2 and 3 reveals that there is an excellent correlation 


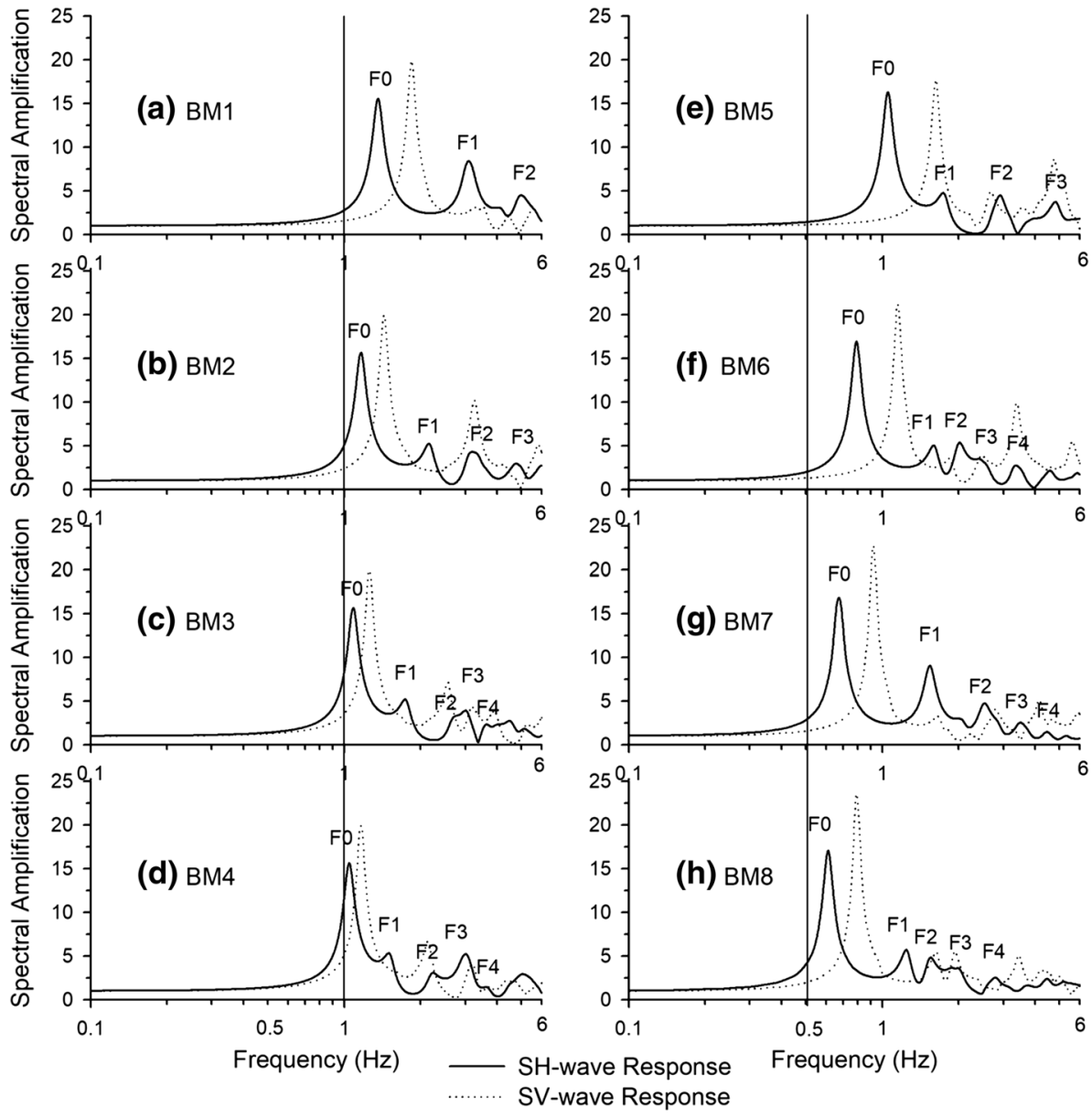

Fig. 4 a-h A comparison of spectral amplifications of the SH-wave and SV-wave at the centre of BM1BM4 rectangular basins, respectively (Table 3)

Table 3 The predicted resonance modes of rectangular basins with different shape ratios for the SH-wave and the same predicted using empirical relation given by Bard and Bouchon (1985)

\begin{tabular}{|c|c|c|c|c|c|c|c|c|c|c|}
\hline \multirow[t]{2}{*}{ Model } & \multicolumn{5}{|c|}{ Numerically predicted modes } & \multicolumn{5}{|c|}{ Modes using relation of Bard and Bouchon (1985) } \\
\hline & $F_{0}$ & $F_{1}$ & $F_{2}$ & $F_{3}$ & $F_{4}$ & $F_{0}(m, n)$ & $F_{1}(m, n)$ & $F_{2}(m, n)$ & $F_{3}(m, n)$ & $F_{4}(m, n)$ \\
\hline BM1 & 1.36 & 3.08 & 4.96 & - & - & $1.38(0,0)$ & $3.03(0,2)$ & $4.86(0,4)$ & - & - \\
\hline BM2 & 1.16 & 2.15 & 3.18 & 4.74 & - & $1.19(0,0)$ & $2.17(0,2)$ & $3.30(0,4)$ & $4.62(0,6)$ & - \\
\hline BM3 & 1.09 & 1.73 & 2.65 & 3.00 & 3.53 & $1.11(0,0)$ & $1.77(0,2)$ & $2.63(0,4)$ & $3.00(1,0)$ & $3.55(0,6)$ \\
\hline BM4 & 1.05 & 1.50 & 2.24 & 3.0 & 3.60 & $1.07(0,0)$ & $1.54(0,2)$ & $2.20(0,4)$ & $3.00(0,6)$ & $3.66(0,8)$ \\
\hline BM5 & 1.04 & 1.73 & 2.90 & 4.81 & - & $1.06(0,0)$ & $1.77(1,0)$ & $2.90(0,2)$ & $4.78(0,4)$ & - \\
\hline BM6 & 0.79 & 1.59 & 2.01 & 2.39 & 3.35 & $0.81(0,0)$ & $1.63(1,0)$ & $1.99(0,2)$ & $2.44(1,2)$ & $3.26(0,4)$ \\
\hline BM7 & 0.68 & 1.55 & 2.52 & 3.49 & 4.45 & $0.69(0,0)$ & $1.54(0,2)$ & $2.49(0,4)$ & $3.45(0,6)$ & $4.41(0,8)$ \\
\hline BM8 & 0.62 & 1.24 & 1.55 & 1.98 & 2.79 & $0.63(0,0)$ & $1.27(0,2)$ & $1.55(1,0)$ & $2.02(0,4)$ & $2.79(0,6)$ \\
\hline
\end{tabular}


between the numerically computed $\mathrm{SH} F_{02 \mathrm{D}}^{\mathrm{B}}$ and $\mathrm{SV} F_{02 \mathrm{D}}^{\mathrm{B}}$ of the basin with the same computed using the empirical relation given by Bard and Bouchon (1985), even the used shape ratio of basins is too large as compared to that taken by Bard and Bouchon (1985).

\subsection{Effects of polarization of S-wave on $F_{02 D}^{S}$ of structure}

The obtained excellent correlation between the numerically computed $\mathrm{SH} F_{02 \mathrm{D}}^{\mathrm{B}}$ and $\mathrm{SV} F_{02 \mathrm{D}}^{\mathrm{B}}$ of basin and the same computed using the empirical relation given by Bard and Bouchon (1985) reflects that the used algorithm is efficient enough to predict the $2 \mathrm{D}$ fundamental frequency of basin or a building block model with a very large shape ratio. Further, the obtained difference between $\mathrm{SH} F_{02 \mathrm{D}}^{\mathrm{B}}$ and $\mathrm{SVF}_{02 \mathrm{D}}^{\mathrm{B}}$ of the same basin develops a curiosity in mind whether 2D fundamental frequency of the structure $\left(F_{02 \mathrm{D}}^{S}\right)$ also depends on the polarization of the incident $\mathrm{S}$-wave. So, to satisfy this curiosity, the effects of shape ratio ( $H / W$, where $H$ is the height of structure and $W$ is the width of the structure) of the building block model on the $\mathrm{SH} F_{02 \mathrm{D}}^{\mathrm{S}}$ and $\mathrm{SVF}_{02 \mathrm{D}}^{\mathrm{S}}$ have been studied and an empirical relation has been developed to predict $\mathrm{SH} F_{02 \mathrm{D}}^{\mathrm{S}}$ and $\mathrm{SV} F_{02 \mathrm{D}}^{\mathrm{S}}$ for the building block models of any shape ratio and polarization of the incident $S$-wave. For this purpose, twelve rock-structure SM1, SM2, SM3, SM4, SM5, SM6, SM7, SM8, SM9, SM10, SM11 and SM12 models (standalone structure situated on the exposed rock) are considered to study the effects of shape ratio of structure on the $\mathrm{SH} F_{02 \mathrm{D}}^{\mathrm{S}}$ and $\mathrm{SV} F_{02 \mathrm{D}}^{\mathrm{S}}$. The parameters like height, width and $F_{01 \mathrm{D}}^{\mathrm{S}}$ of the SM1-SM12 building block models are given in Table 4. The SH-wave and SV-wave responses of structures are commonly known as antiplane and inplane excitation of structures, respectively, in the field of structural dynamics. A comparison of the antiplane and inplane responses of the SM1-SM4 rock-structure models is shown in Fig. 5. The analysis

Table 4 The 1D fundamental frequency of structure $\left(F_{01 \mathrm{D}}^{\mathrm{S}}\right), 2 \mathrm{D}$ fundamental frequency of structure $\left(\mathrm{S}_{02 \mathrm{D}}^{\mathrm{S}}\right)$ and largest SAF at $F_{02 \mathrm{D}}^{\mathrm{S}}$ in case of various structure models excited by the SH-wave and the SV-wave

\begin{tabular}{|c|c|c|c|c|c|c|c|c|c|}
\hline \multirow[t]{2}{*}{$\begin{array}{l}\text { Structure } \\
\text { models }\end{array}$} & \multirow[t]{2}{*}{$\begin{array}{l}\text { Height } q \\
(\mathrm{~m})\end{array}$} & \multirow[t]{2}{*}{$\begin{array}{l}\text { Width } W \\
(\mathrm{~m})\end{array}$} & \multirow[t]{2}{*}{ Shape ratio } & \multirow[t]{2}{*}{$F_{01 \mathrm{D}}^{S} \mathrm{~Hz}$} & \multicolumn{2}{|c|}{$\begin{array}{l}\mathrm{SH} F_{02 \mathrm{D}}^{\mathrm{S}}(\mathrm{Hz}) \text { of } \\
\text { structure and } \\
\mathrm{SAF} \text { for } \mathrm{SH}- \\
\text { wave }\end{array}$} & \multicolumn{3}{|c|}{$\begin{array}{l}\mathrm{SVF}_{02 \mathrm{D}}^{\mathrm{S}}(\mathrm{Hz}) \text { of structure } \\
\text { and SAF for SV-wave }\end{array}$} \\
\hline & & & & & $\mathrm{SH} F_{02 \mathrm{D}}^{\mathrm{S}}$ & SAF & $\mathrm{SVF}_{02 \mathrm{D}}^{\mathrm{S}}$ & SAF & $\begin{array}{l}\mathrm{SVF}_{02 \mathrm{D}}^{\mathrm{S}} \\
\text { using } \\
\text { Eq. } 4\end{array}$ \\
\hline SM1 & 30 & 63 & 0.47 & 1.0 & 0.97 & 13.19 & 0.81 & 16.88 & 0.81 \\
\hline SM2 & 30 & 93 & 0.32 & 1.0 & 0.97 & 13.13 & 0.86 & 15.23 & 0.86 \\
\hline SM3 & 30 & 123 & 0.24 & 1.0 & 0.97 & 13.07 & 0.88 & 14.26 & 0.88 \\
\hline SM4 & 30 & 153 & 0.19 & 1.0 & 0.97 & 13.00 & 0.89 & 14.39 & 0.89 \\
\hline SM5 & 60 & 63 & 0.95 & 0.5 & 0.49 & 13.43 & 0.33 & 18.21 & 0.33 \\
\hline SM6 & 60 & 93 & 0.64 & 0.5 & 0.49 & 13.39 & 0.38 & 18.89 & 0.38 \\
\hline SM7 & 60 & 123 & 0.48 & 0.5 & 0.49 & 13.34 & 0.41 & 18.79 & 0.40 \\
\hline SM8 & 60 & 153 & 0.39 & 0.5 & 0.49 & 13.30 & 0.42 & 17.12 & 0.42 \\
\hline SM9 & 15 & 33 & 0.45 & 2.0 & 1.98 & 11.88 & 1.60 & 13.09 & 1.63 \\
\hline SM10 & 30 & 33 & 0.90 & 1.0 & 0.97 & 13.32 & 0.66 & 20.98 & 0.67 \\
\hline SM11 & 45 & 33 & 1.36 & 0.66 & 0.65 & 13.56 & 0.35 & 20.52 & 0.35 \\
\hline SM12 & 60 & 33 & 1.81 & 0.5 & 0.49 & 13.22 & 0.20 & 18.66 & 0.19 \\
\hline
\end{tabular}


of Fig. 5 depicts that the antiplane responses are identical in the rock-structure models. The maximum value of amplitude and duration in antiplane response for all the SM1-SM4 models is same. But, in the case of inplane responses of the structure-rock models, there are tremendous effects of shape ratio of structure on the response. An increase in amplitude of the incident $\mathrm{SV}$-wave with a decrease in shape ratio can be inferred.

Figure $6 \mathrm{a}-\mathrm{h}$ shows the comparison of spectral amplifications of the SH-wave and SVwave at the top of SM1-SM8 rock-structure models, respectively, with respect to the exposed rock. The $F_{02 \mathrm{D}}^{\mathrm{S}}$ of all the structures for the $\mathrm{SH}$ - and $\mathrm{SV}$-waves and the corresponding SAF at these frequencies are also given in Table 4. Analysis of Table 4 depicts that there is almost no effect of change of width of structure on the $\mathrm{SH} F_{02 \mathrm{D}}^{\mathrm{S}}(0.97 \mathrm{~Hz}$ in case of 10 -storey structure) and the corresponding SAF. The value of peak acceleration $(17.5 \mathrm{~mm} /$ $\mathrm{s}^{2}$ ), peak velocity $(1.69 \mathrm{~mm} / \mathrm{s})$, peak displacement $(1.48 \mathrm{~mm})$ and Fourier spectra $(\mathrm{SH}$ $\left.F_{02 \mathrm{D}}^{\mathrm{S}}=0.97 \mathrm{~Hz}, \mathrm{SAF}=13.1\right)$ for all the SM1-SM4 rock-structure models are same, which satisfies the C5, C6, C7 and C9 numbers of goodness-of-fit measurement of Anderson (2004) criteria to match the similarity of two time histories. In contrast to this, in case of inplane $\mathrm{S}$-wave responses of these models, there is a drastic decrease in $\mathrm{SV} F_{02 \mathrm{D}}^{\mathrm{S}}$ of structure with the increase in shape ratio of structure. For example, $S V F_{02 \mathrm{D}}^{\mathrm{S}}$ of the 10-storey SM1-SM4 rock-structure models are $0.81 \mathrm{~Hz}, 0.86 \mathrm{~Hz}, 0.88 \mathrm{~Hz}$ and $0.89 \mathrm{~Hz}$, respectively. Similarly, SVF $F_{02 \mathrm{D}}^{\mathrm{S}}$ of the 20-storey rock-structure SM5-SM8 models are $0.33 \mathrm{~Hz}, 0.38 \mathrm{~Hz}$, $0.41 \mathrm{~Hz}$ and $0.42 \mathrm{~Hz}$, respectively. Similarly, it can also be stated that there is a systematic increase in $\mathrm{SAF}$ at $\mathrm{SV} F_{02 \mathrm{D}}^{\mathrm{S}}$ with the increase in shape ratio. Further, the SAF at $F_{02 \mathrm{D}}^{\mathrm{S}}$ in the case of 20-storey structure is more than as compared with that in the case of 10-storey structures in both the antiplane and inplane responses. The SAF at $\mathrm{SVF}_{02 \mathrm{D}}^{\mathrm{S}}$ is also larger than that at $\mathrm{SH} F_{02 \mathrm{D}}^{\mathrm{S}}$ for a particular shape ratio of structure.

This can be concluded that in the case of antiplane excitation of structure, $\mathrm{SH} F_{02 \mathrm{D}}^{\mathrm{S}}$ of structure and corresponding SAF are independent of width, and it depends only on the height of structure. In the case of 2D structure modelling, the third side (perpendicular the plane) is assumed to be infinite or very long with respect to other two sides. That's why

SH-wave Response

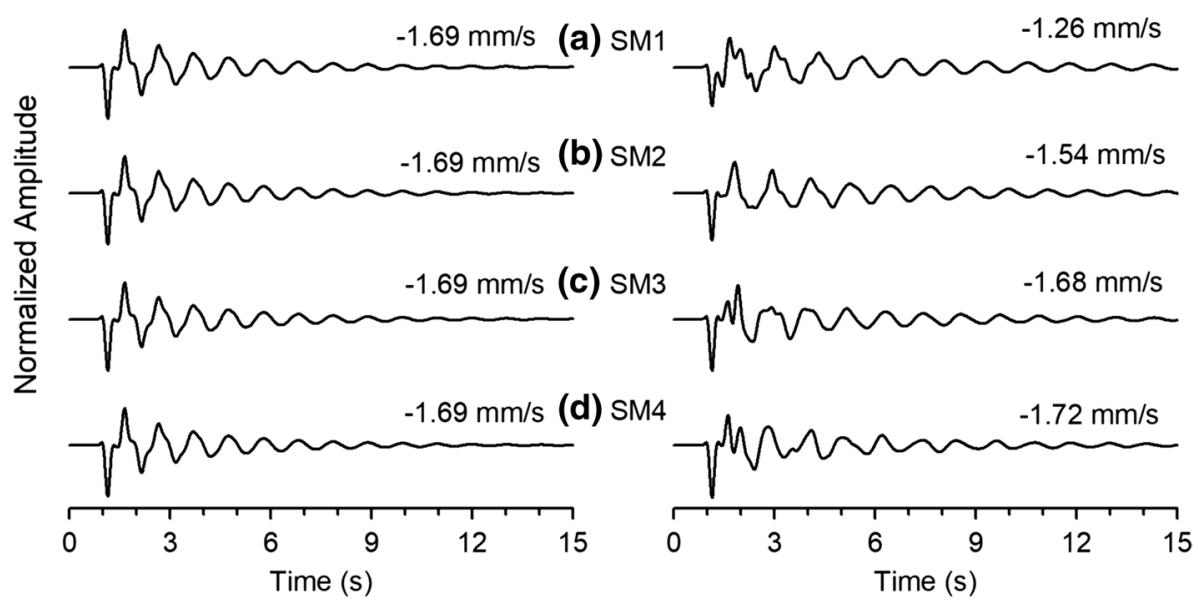

Fig. 5 a-d The SH-wave (left panel) and the horizontal component of the SV-wave (right panel) responses at the top of the SM1-SM4 building block models, respectively (Table 4) 


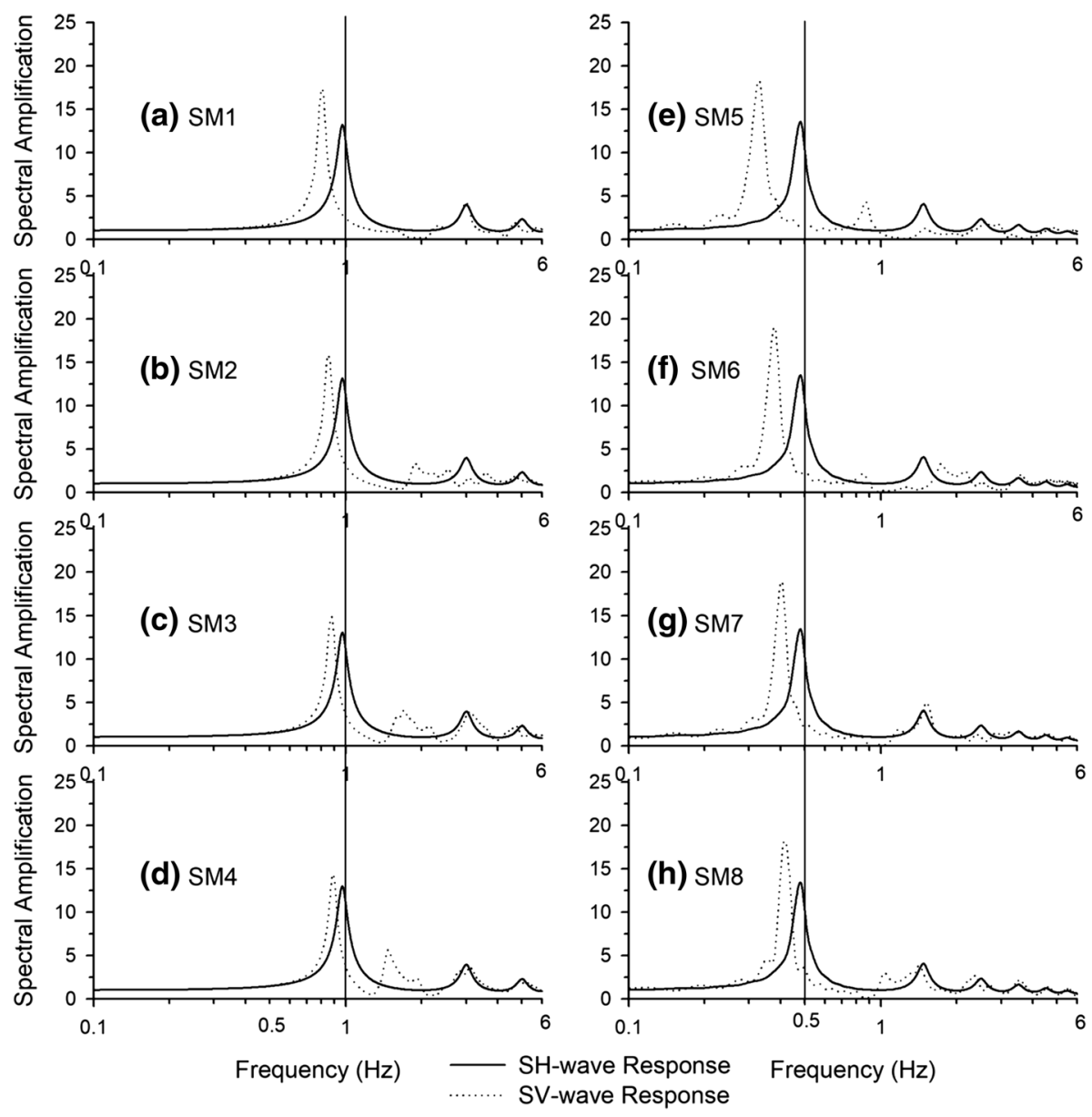

Fig. 6 a-h A comparison of spectral amplifications of the SH-wave and the SV-wave at the top of SM1SM8 building block models, respectively (Table 4)

in case of antiplane simulation, only shear force acts resulting in stiffness that is inversely proportional to the height of structure. Hence, fundamental frequency is inversely proportional to the height of structure. On the other hand, in the case of inplane excitation of structure, there will be rocking and translational motion. So, stiffness is directly proportional to the width of structure and inversely proportional to the height of the structure. Therefore, there is a tremendous decrease in $S V F_{02 \mathrm{D}}^{\mathrm{S}}$ of structure with the increase in shape ratio as compared to $F_{01 \mathrm{D}}^{\mathrm{S}}$ of structure.

To study the effects of change of height of structure, we have considered four more rock-structure models SM9, SM10, SM11 and SM12. The width is kept constant $(33 \mathrm{~m})$, and height is changed $15 \mathrm{~m}, 30 \mathrm{~m}, 45 \mathrm{~m}$ and $60 \mathrm{~m}$ for the SM9-SM12 models, respectively. The SM11 and SM12 models are also important, as in these models the height is greater than width $(H>W)$, which are very common for intermediate- and high-rise buildings. But, in the case of basins, this scenario is very rare in nature, so it is not considered in this paper. The comparison of responses of the SM9-SM12 rock-structure models for 


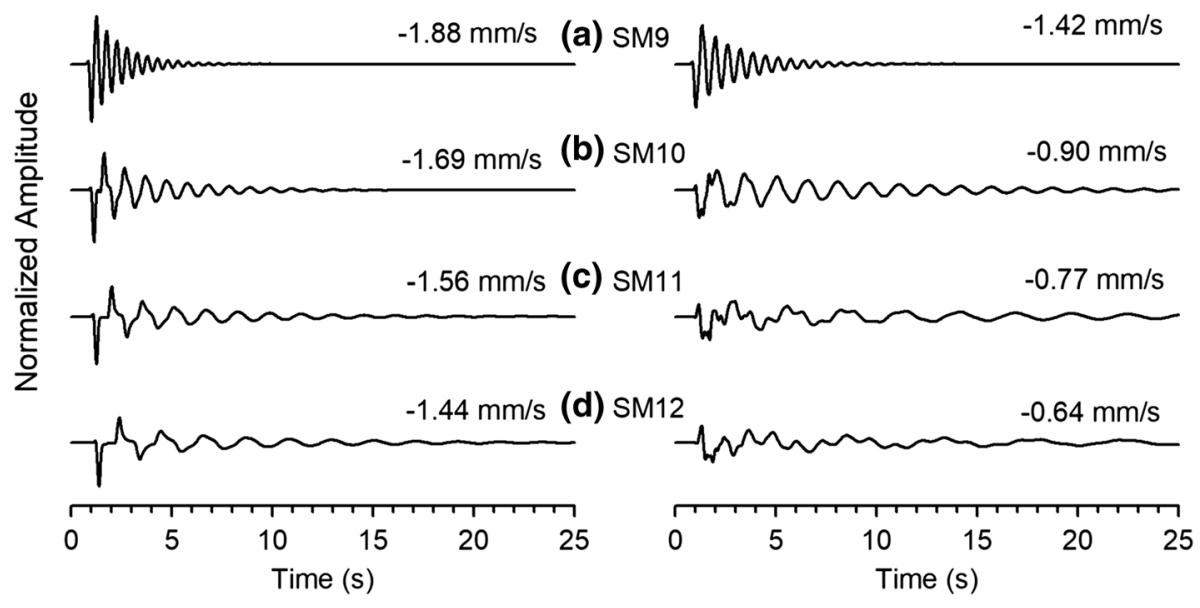

Fig. 7 a-d The SH-wave (left panel) and SV-wave (right panel) responses at the top of the SM9-SM12 building block models, respectively (Table 4)
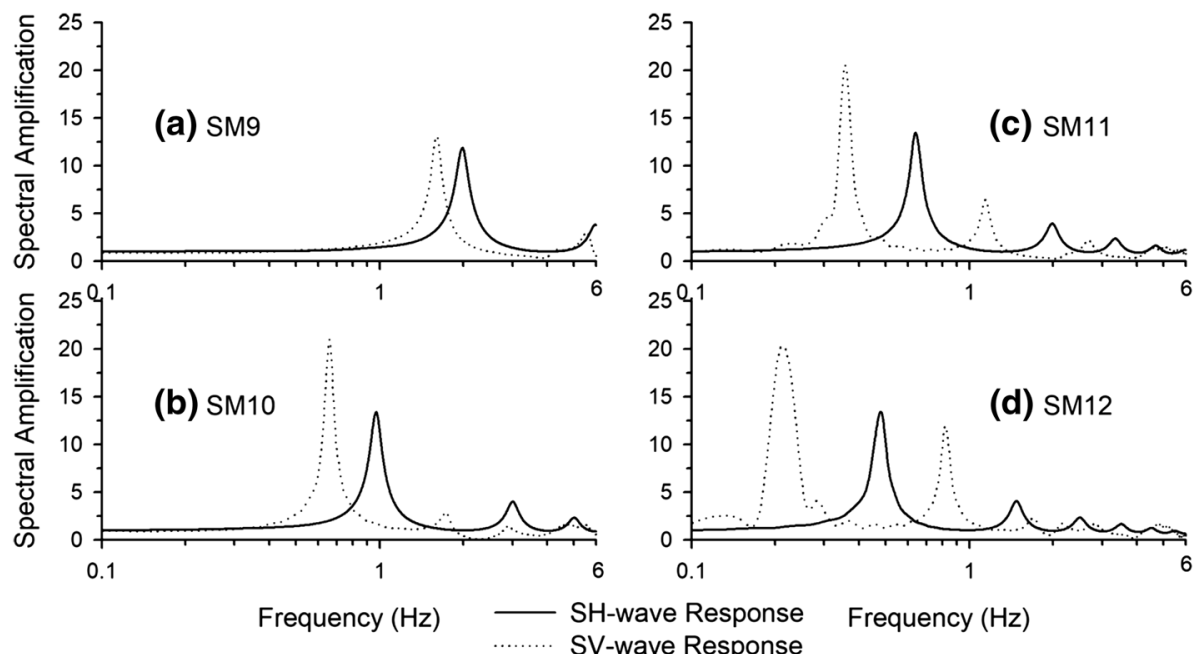

Fig. 8 a-d A comparison of spectral amplifications of the SH-wave and SV-wave at the top of SM9-SM12 building block models, respectively (Table 4)

antiplane and inplane excitations is shown in Fig. 7. The analysis of this figure depicts that in both cases there is increase in duration and decrease in maximum amplitude as the shape ratio increases. Further, the duration of signal in the case of inplane is more than that in the antiplane. A comparison of spectral amplifications of SH- and SV-waves at the top of SM9-SM12 rock-structure models is shown in Fig. 8. The $\mathrm{SH} F_{02 \mathrm{D}}^{\mathrm{S}}$ of structure matches with its $F_{01 \mathrm{D}}^{\mathrm{S}}$, whereas in the case of $\mathrm{SV} F_{02 \mathrm{D}}^{\mathrm{S}}$ of structure, it is always less than $F_{01 \mathrm{D}}^{\mathrm{S}}$ for all the considered cases. In order to predict the reduced $S V F_{02 \mathrm{D}}^{\mathrm{S}}$ of structure for the $\mathrm{SV}$-wave 
in terms of $F_{01 \mathrm{D}}^{\mathrm{S}}$ for any height of structure, a graph has been drawn between the ratio $\mathrm{SVF} F_{02 \mathrm{D}}^{\mathrm{S}} / F_{01 \mathrm{D}}^{\mathrm{S}}$ and the shape ratio of the structure, as shown in Fig. 9. This figure clearly reflects the decrease in $\mathrm{SVF} F_{02 \mathrm{D}}^{\mathrm{S}} / F_{01 \mathrm{D}}^{\mathrm{S}}$ ratio with an increase in shape ratio, irrespective of height of the structure. Based on the best-fit criterion, an empirical relation between $\mathrm{SVF}_{02 \mathrm{D}}^{S} / F_{01 \mathrm{D}}^{S}$ and shape ratio of structures is obtained as given below

$$
\frac{\mathrm{SV} F_{02 \mathrm{D}}^{S}}{F_{01 \mathrm{D}}^{S}}=\left[\frac{\left\{3-\left(\frac{H}{W}\right)\right\}}{3.2}\right]
$$

\section{Fundamental frequency of single structure in 1D basin $\left(F_{02 \mathrm{D}}^{\mathrm{BS}}\right)$}

The findings of subsections 2 and 3 revealed an increase and decrease in 2D fundamental frequencies of basin and structure, respectively, with an increase in respective shape ratio. Now, this scenario put up a question whether there may be an increase or a decrease in 2D fundamental frequency of the structure situated in a 1D basin, particularly in the case of $\mathrm{SV}$-wave, where there is a considerable reduction in fundamental frequency of structure. Second question may also arise, what may happen if the structure is in resonance with the 1D basin $\left(F_{02 \mathrm{D}}^{\mathrm{S}}=F_{01 \mathrm{D}}^{\mathrm{B}}\right)$. For this purpose, four basin-structure BD1, BD2, BD3 and BD4 models of varying basin depths are considered for the computation of SH-wave and $\mathrm{SV}$-wave responses at the top of a single 10-storey structure (height $30 \mathrm{~m}$ and width $63 \mathrm{~m}$ ) situated in basin. The parameters of sediment of basin and underlying rock are given in Table 1. The dimension of structure is same in all the considered models, but the depth of basin has been taken $174 \mathrm{~m}, 108 \mathrm{~m}, 87 \mathrm{~m}$ and $60 \mathrm{~m}$ to vary $F_{01 \mathrm{D}}^{\mathrm{B}}$ of the basin in BD1-BD4 models, respectively. The $F_{01 \mathrm{D}}^{\mathrm{B}}$ of the considered basins for the BD1-BD4 models is $0.5 \mathrm{~Hz}, 0.8 \mathrm{~Hz}, 1.0 \mathrm{~Hz}$ and $1.46 \mathrm{~Hz}$, respectively (Table 5).

Figure 10a-d depicts a comparison of the spectral amplifications of the SH-wave and $\mathrm{SV}$-wave, respectively, at the top of the 10-storey structure situated in a basin with different $F_{01 \mathrm{D}}^{\mathrm{B}}$. An analysis of Fig. 10 and Table 5 depicts that the first spectral amplification peak

Fig. 9 Variation of ratio of $2 \mathrm{D}$ to 1D fundamental frequency of the stand-alone building block model on the rock for the SV-wave with the shape ratio

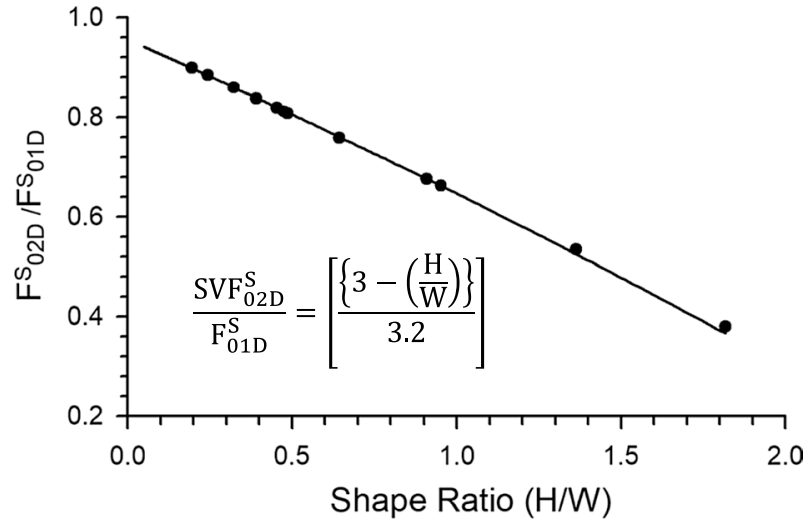




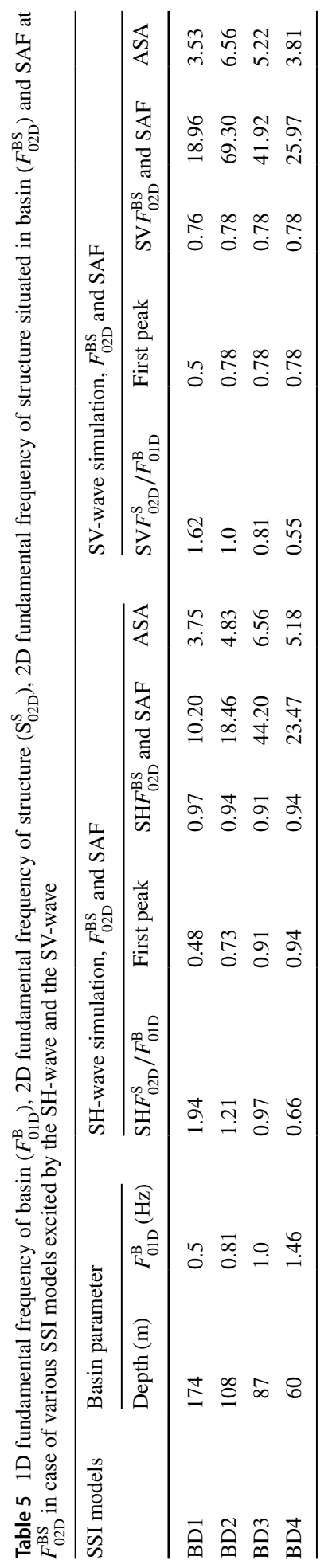




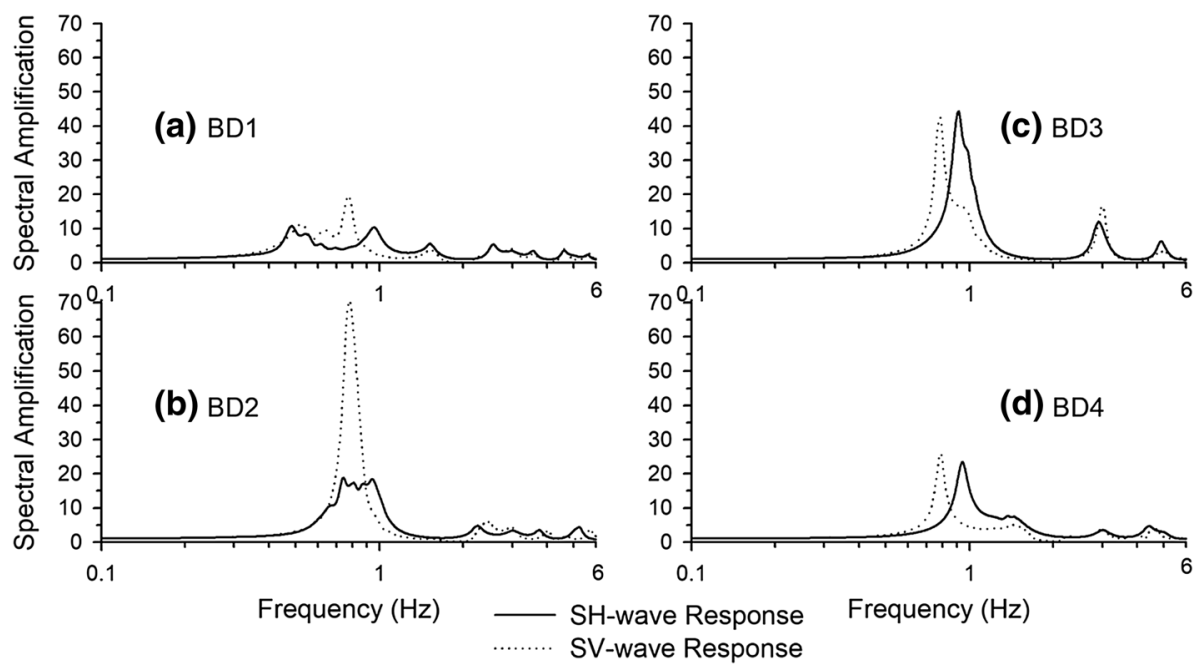

Fig. 10 a-d A comparison of spectral amplifications of the SH- and the SV-waves at the top of the BD1BD4 building block models, respectively, situated at the centre of a rectangular basin of different shape ratios

is governed by the $F_{01 \mathrm{D}}^{\mathrm{B}}$ of basin, if it is less than the $F_{02 \mathrm{D}}^{\mathrm{S}}$ of the structure; otherwise, it is governed by the $F_{02 \mathrm{D}}^{\mathrm{S}}$ of the structure. There is a negligible decrease in the value of $\mathrm{SV} F_{02 \mathrm{D}}^{\mathrm{BS}}$ of structure for the $\mathrm{SV}$-wave, and this decrease is unaffected by the increase in $F_{01 \mathrm{D}}^{\mathrm{B}}$ of the $1 \mathrm{D}$ basin. In contrast to this, there is a considerable decrease in the value of $\mathrm{SH} F_{02 \mathrm{D}}^{\mathrm{BS}}$ of the structure for the $\mathrm{SH}$-wave, when $\mathrm{SH} F_{02 \mathrm{D}}^{\mathrm{BS}}$ of structure is matching with $F_{01 \mathrm{D}}^{\mathrm{B}}$ of the basin. However, the decrease in $\mathrm{SH} F_{02 \mathrm{D}}^{\mathrm{BS}}$ of structure is decreasing when the difference between $\mathrm{SH} F_{02 \mathrm{D}}^{\mathrm{BS}}$ and $F_{01 \mathrm{D}}^{\mathrm{B}}$ is increasing. The $\mathrm{SH} F_{02 \mathrm{D}}^{\mathrm{S}}$ and $\mathrm{SV} F_{02 \mathrm{D}}^{\mathrm{S}}$ of 10 -storey structure (height $=30$ and width $=63 \mathrm{~m}$ ) are 0.97 and $0.81 \mathrm{~Hz}$, respectively. In the case of SH-wave simulation, the ratio of $\mathrm{SH} F_{02 \mathrm{D}}^{\mathrm{S}}$ to that of $F_{01 \mathrm{D}}^{\mathrm{B}}$ is obtained as $1.94,1.21,0.97$ and 0.66 , and their respective SAF values are 10.20, 18.46, 44.20, and 23.47 for BD1, BD2, BD3 and BD4 models, respectively. Similarly, in the case of SV-wave simulation, the $\mathrm{SV} F_{02 \mathrm{D}}^{\mathrm{S}} / F_{01 \mathrm{D}}^{\mathrm{B}}$ ratios are 1.62, 1.0, 0.81 and 0.55 and their respective $\mathrm{SAF}$ values are 18.96, 69.30, 41.92 and 25.97 for BD1, BD2, BD3 and BD4 models, respectively. The occurrence of double resonance phenomenon $\left(F_{02 \mathrm{D}}^{\mathrm{BS}}=F_{01 \mathrm{D}}^{\mathrm{B}}\right)$ has caused very large amplification at $F_{02 \mathrm{D}}^{\mathrm{BS}}$ of structure in the basin. The value of SAF at $F_{02 \mathrm{D}}^{\mathrm{BS}}$ of structure decreases exponentially as the ratio of $F_{02 \mathrm{D}}^{\mathrm{S}} / F_{01 \mathrm{D}}^{\mathrm{B}}$ moves away from 1.0. Average spectral amplification (ASA) values also follow the same pattern representing the maximum value when the ratio $F_{02 \mathrm{D}}^{\mathrm{S}} / F_{01 \mathrm{D}}^{\mathrm{B}}$ is equal to 1 . The ASA values obtained at the top of structure in the BD1-BD4 basin-structure models corresponding to the SH-wave and SV-wave simulations are given in Table 5.

\section{$5 \mathrm{SCl}$ effects on $\boldsymbol{F}_{02 \mathrm{D}}^{\mathrm{BS}}$ of structure and SAF}

In this subsection, site-city interaction (SCI) effects on the responses of 10-storey structures (height $30 \mathrm{~m}$ and width $63 \mathrm{~m}$ ) situated in a 1D basin are studied in detail. The variation of 2D fundamental frequency of structure situated in basin $\left(\boldsymbol{F}_{02 \boldsymbol{D}}^{\boldsymbol{B} \boldsymbol{S}}\right)$ with city density, number of structures (constant city density), location of structure in the city and 
polarization of the incident $S$-wave as well as SAF at $\boldsymbol{F}_{02 \boldsymbol{D}}^{\boldsymbol{B} S}$ is quantified. The effects of SCI on the free-field motion when both the 1D basin and 2D structures are under double resonance condition are also quantified. In order to develop the double resonance scenario in the entire city, the $F_{01 \mathrm{D}}^{\mathrm{B}}$ of the $1 \mathrm{D}$ basin is taken as $0.97 \mathrm{~Hz}$ and $0.81 \mathrm{~Hz}$ for the SH-wave and SV-wave simulations, respectively, since the corresponding $F_{02 \mathrm{D}}^{\mathrm{S}}$ of the 10-storey structure is 0.97 and 0.81 . The detail of site-city model consisting of 13 structures, basin and bedrock along with the position of receivers with respect to distance from the centre of city is shown in Fig. 11. The receiver kept at the top of seventh structure at the centre of city is denoted as ' $\mathrm{C} 0$ ', and receivers kept at the top of eighth to thirteenth structures towards right of the centre of city are denoted as R1-R6, respectively. Similarly, the receivers kept at the top of sixth to first structures towards left of the centre of city are denoted as L1-L6, respectively. The receiver kept at the free surface at a distance of $525 \mathrm{~m}$ towards the left and right of the city is denoted as 'LG' and 'RG', respectively.

\section{$5.1 \mathrm{SCl}$ effects (constant city density)}

The considered constant city density CD1S, CD5S, CD9S and CD13S models containing 1, 5, 9 and 13 structures, respectively, for the computation of the SH- and SV-wave responses are shown in Fig. 12a-d. The distance between two structures is taken as $12 \mathrm{~m}$ in the entire city to make sure that city density is constant. The parameters of the 1D basin for the simulation of SH-wave and SV-wave responses are given in Table 6. The SH-wave and SV-wave responses of the considered site-city models were simulated at the top of the buildings as well as at a distance of $45 \mathrm{~m}$ from the respective city at the free surface to see the effects of city density on the free-field motion under double resonance condition. The response of structure of CD1S model is considered as a reference one for the quantification of SCI effects on the response of structure.

\section{Distance from center of city in meter (' $x$ ')}

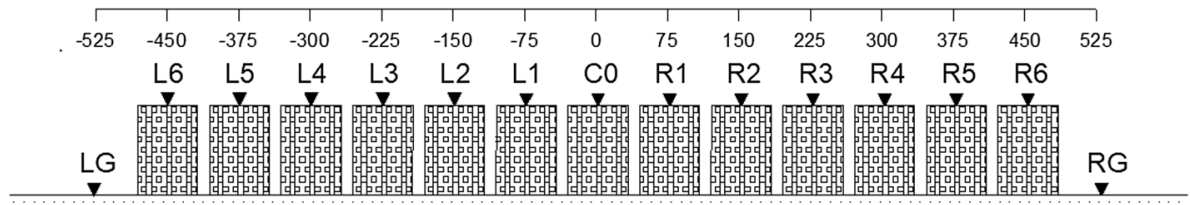

Basin

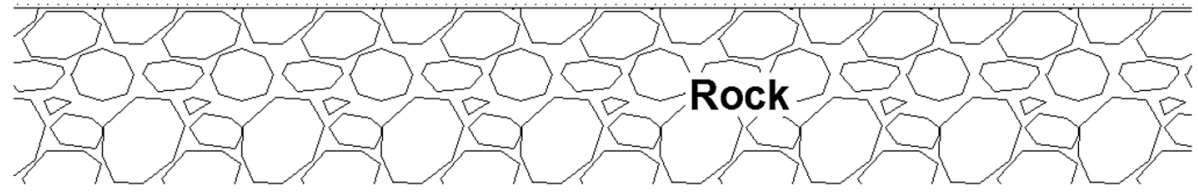

Fig. 11 Site-city model consisting of 13-storey structures, basin and bedrock (note: C0, L6-L1 and R1-R6, denote the position of receivers with respect to the centre of the city and at the top of structure at the centre of city, at the top of first to sixth structures and at the top of eighth to thirteenth structures, respectively. The LG and RG are the location of receivers at the free surface towards left and right of the city at a distance of $45 \mathrm{~m})$ 


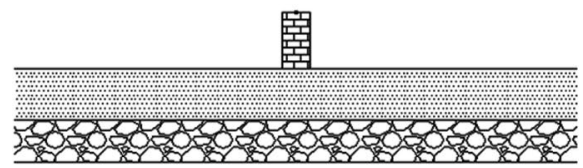

(a) $\mathrm{CD} 1 \mathrm{~S}$

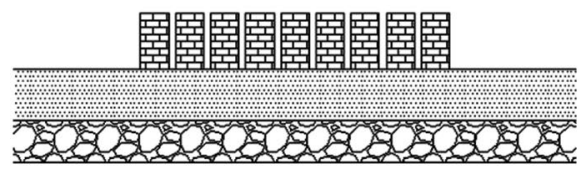

(c) $\operatorname{CD9S}$

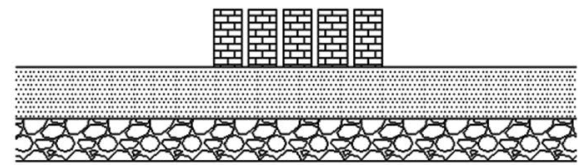

(b) CD5S

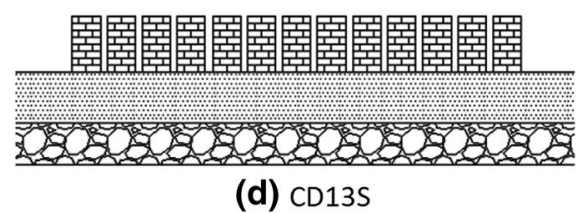

Fig. 12 a-d The CD1S, CD5S, CD7S and CD13S site-city models with a constant city density (note: the position of receiver points at the top of structures and at the free surface is in accordance with as shown in Fig. 11)

\subsubsection{SH-wave response}

A comparison of spectral amplifications of the SH-wave at the top of the structure situated at the centre $(\mathrm{C} 0)$, receivers R2, R4 and R6 of the CD1S, CD5S, CD9S and CD13S SCI models as well as at the free surface (RG) is shown in the left panel of Fig. 13a-e, respectively. The analysis of this Fig. 13a depicts that soil-structure interaction has caused a minor reduction in the value of $\mathrm{SH}_{02 \mathrm{D}}^{\mathrm{BS}}(0.91 \mathrm{~Hz})$ as compared to the value of $\mathrm{SH} F_{02 \mathrm{D}}^{\mathrm{S}}$ $(0.97 \mathrm{~Hz})$ of stand-alone structure on rock. Further, the spectral amplification at $\mathrm{SH} F_{02 \mathrm{D}}^{\mathrm{BS}}$ of stand-alone structure in basin is of the order of 44.2. However, in case of the CD5S, CD9S and CD13S SCI models a splitting of the spectral bandwidth of $\mathrm{SH} F_{02 \mathrm{D}}^{\mathrm{BS}}$ of structure in basin into two or more peaks can be inferred. Further, there is a drastic reduction in SAF in the spectral bandwidth of $\mathrm{SH}_{02 \mathrm{D}}^{\mathrm{BS}}$. For example, the largest $\mathrm{SAF}$ is of the order of only 26.47, 32.18 and 30.66 in the CD5S, CD9S and CD13S SCI models, respectively, which are much lesser than that in the case of CD1S model (44.2). The obtained frequency corresponding to the first spectral amplification peak as $0.86 \mathrm{~Hz}, 0.84 \mathrm{~Hz}$ and $0.79 \mathrm{~Hz}$ and corresponding SAF as 22.64, 17.76 and 14.22 in the CD5S, CD9S and CD13S SCI models, respectively, reveals the reduction in value of both the frequency and the corresponding SAF with the increase in number of structures in the city. Further, the largest SAF may occur on first or second spectral ratio peak in the frequency bandwidth of $\mathrm{SH} F_{02 \mathrm{D}}^{\mathrm{BS}}$. Furthermore, in the central part of the city, there is a trough in the frequency bandwidth of $\mathrm{SH} F_{02 \mathrm{D}}^{\mathrm{BS}}$ and the SAF at the base of spectral ratio trough is 7.55, 4.28 and 6.40 in the CD5S, CD9S and CD13S SCI models, respectively. The obtained average spectral amplification (ASA) in the frequency bandwidth of fundamental mode as 6.49, 5.16, 5.37 and 5.42 corresponding to the CD1S, CD5S, CD9S and CD13S SCI models, respectively, reflects that there is a considerable decrease in ASA also due to the SCI effects. However, the inferred SCI effects on the reduction in SAF and the splitting of frequency bandwidth of first and higher modes are not so prominent.

The analysis of the left panel of Fig. 13b-d depicts the decrease in potential of SCI effects to reduce the SAF and split the frequency bandwidth of the fundamental mode with the increase in distance of a structure from the centre of the city. For example, the largest SAF in the frequency bandwidth of fundamental mode is $21.88,20.49,18.30,25.12$, 29.31 and 30.66 at the top of $2 \mathrm{nd} 3 \mathrm{rd}, 4 \mathrm{th}, 5 \mathrm{th}$, 6th and 7 th structures, respectively, from 


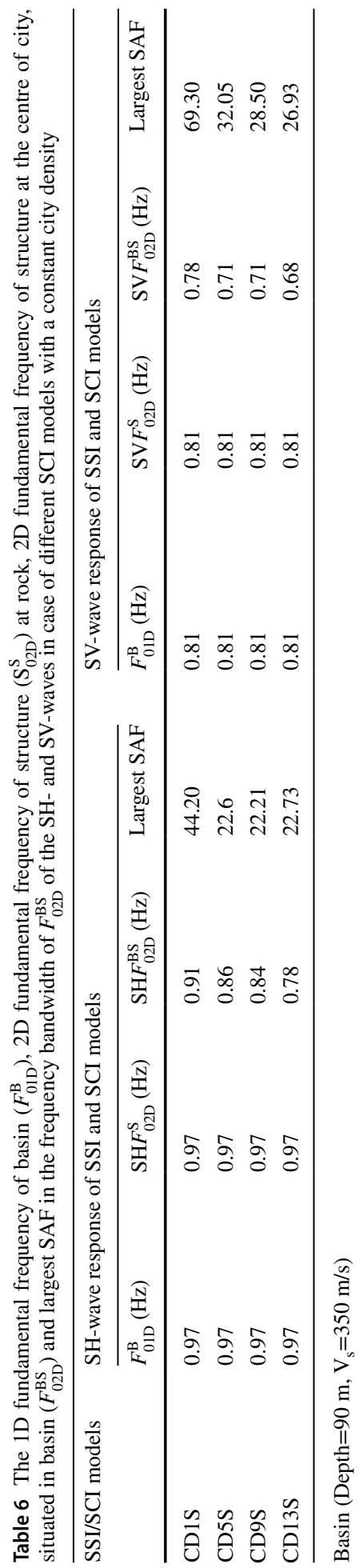



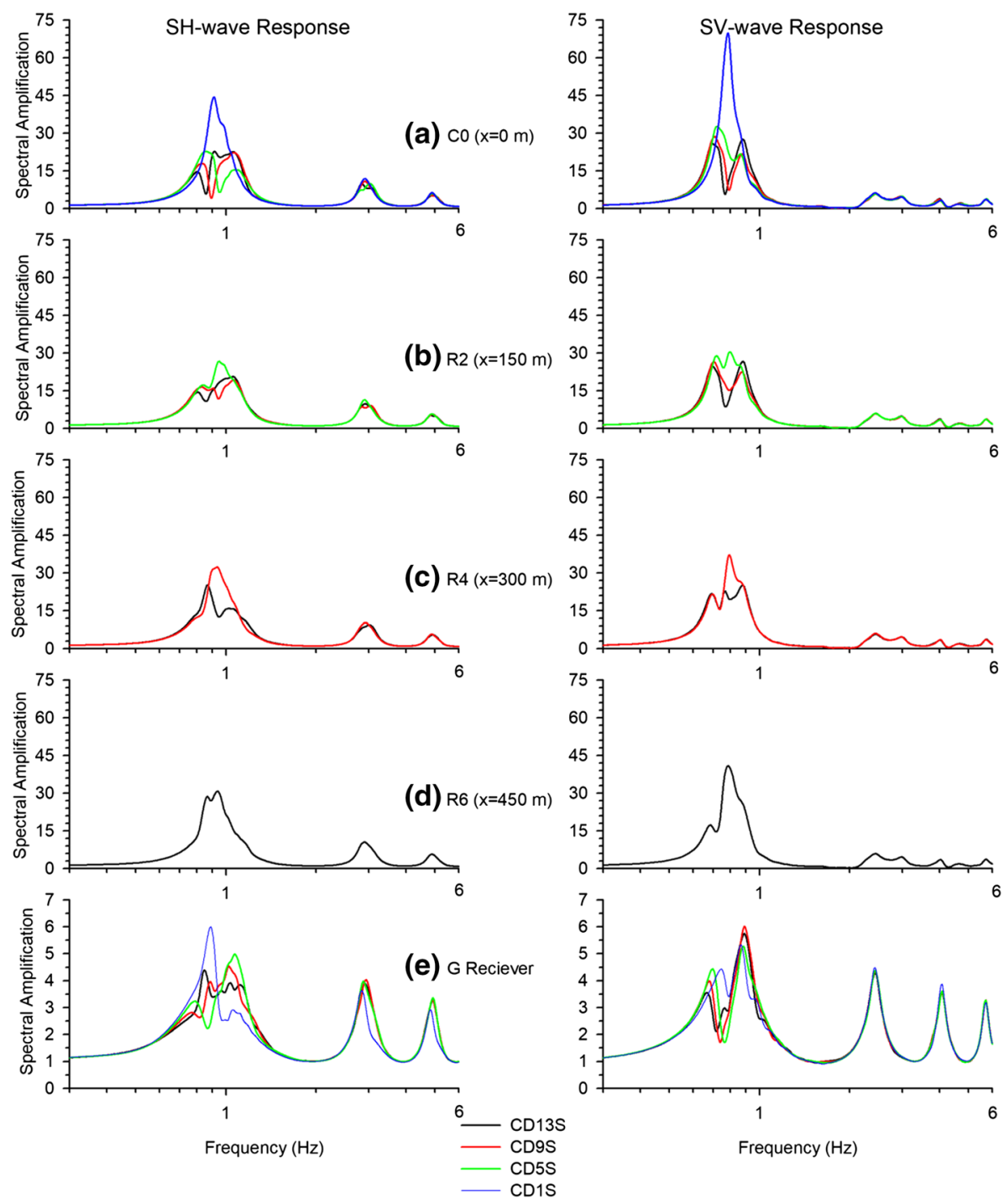

Fig. 13 a-d A comparison of spectral amplifications of the SH-wave (left panel) and SV-wave (right panel) at the top of the structures from the centre of various site-city models with a constant city density and $\mathbf{e}$ at the free surface in basin at a distance of $45 \mathrm{~m}$ from the left edge of the respective city

the centre of the CD13S SCI model. The left panel of Fig. 13e depicts the comparison of spectral amplifications at the free surface at an offset of $45 \mathrm{~m}$ from the respective city. A minor decrease in SAF in bandwidth of fundamental mode but a minor increase in SAF in the bandwidth of higher modes of vibrations of basin can be inferred with an increase in number of structures in the city. However, the obtained ASA in the frequency bandwidth of fundamental mode as 1.82, 1.88, 1.87, 1.87 corresponding to CD1S, CD5S, CD9S and CD13S SCI models, respectively, reflects that there is a negligible increase in ASA with the increase in number of structures in the city. 


\subsubsection{SV-wave response}

A comparison of the spectral amplifications of the SV-wave at the top of the central structure of the CD1S, CD5S, CD9S and CD13S SCI models is shown in the right panel of Fig. 13a. In the case of CD5S, CD9S and CD13S SCI models, a splitting of the spectral bandwidth of $S V F_{02 \mathrm{D}}^{\mathrm{BS}}$ of structure into two or three peaks can also be inferred, as was observed in the SH-wave responses. Further, there is a drastic reduction in SAF in the spectral bandwidth of SVF $F_{02 \mathrm{D}}^{\mathrm{BS}}$. For example, the largest $\mathrm{SAF}$ is of the order of only $32.05,28.50$ and 26.93 in the CD5S, CD9S and CD13S SCI models, respectively, which are much lesser than that in the CD1S model (69.3). The obtained frequency corresponding to the first spectral amplification peak as $0.71 \mathrm{~Hz}, 0.71 \mathrm{~Hz}$ and $0.68 \mathrm{~Hz}$ and SAF as 32.05, 28.50 and 25.45 in the CD5S, CD9S and CD13S SCI models, respectively, reveals the reduction in values of both the frequency and corresponding SAF with the increase in number of structures in the city. Further, the largest SAF may occur on first or second spectral ratio peak in the frequency bandwidth of $\mathrm{SVF}_{02 \mathrm{D}}^{\mathrm{BS}}$. Furthermore, in this case also, there is a trough in the frequency bandwidth of $S V F_{02 \mathrm{D}}^{\mathrm{BS}}$ whose value is very clearly decreasing with the increase in number of structures in the city. The obtained ASA in the frequency bandwidth of SVF $F_{02 \mathrm{D}}^{\mathrm{BS}}$ as 6.32, 4.87, 4.60 and 4.77 corresponding to the CD5S, CD9S and CD13S SCI models, respectively, reflects that there is a considerable decrease in ASA due to the increase in number of structures in the SCI models. Further, in the case of SV-wave, the obtained ASA in the frequency bandwidth of $\mathrm{SVF}_{02 \mathrm{D}}^{\mathrm{BS}}$ is lesser as compared to that in case of SH-wave.

The analysis of spectral amplifications of the horizontal component of the SV-wave at the top of the structures excluding the central one also depicts the decrease in potential of SCI effects to reduce the SAF and split the frequency bandwidth of the fundamental mode with the increase in distance of a structure from the centre of the city (right panels of Fig. 13b-d). The right panel of Fig. 13e depicts the spectral amplification of SV-wave at the free surface at an offset of $45 \mathrm{~m}$ from the respective city. A minor increase in SAF in bandwidth of fundamental mode but a minor increase in SAF in the bandwidth of higher modes of vibrations of basin can be inferred with an increase in number of structures. The obtained ASA in the frequency bandwidth of fundamental mode as 1.79, 1.78, 1.80, 1.78 corresponding to CD1S, CD5S, CD9S and CD13S SCI models (Fig. 13e, right panel), respectively, reflects that there is almost no effect of increase in number of structures in city on the free-field motion.

\section{$5.2 \mathrm{SCl}$ effects (variable city density)}

In order to study the effects of variable city density (VD) on the SH- and SV-wave response of structures and the free-field ground motion, the considered SCI models contain different numbers of structures in a fixed span of city $(963 \mathrm{~m})$ situated in a 1D basin. The number of 10-storey structures in the considered four SCI models, namely VD3S, VD5S, VD9S and VD13S, for the computation of SH- and SV-wave responses is 3, 5, 7 and 13, respectively, as shown in Fig. 14a-d. So, the city density for the VD3S, VD5S, VD9S and VD13S SCI models is $0.19,0.32,0.45$ and 0.85 , respectively. The left and right panels of Fig. 15a-d depict a comparison of SH-wave and SV-wave responses, respectively, at the top of a central structure of the VD3S, VD5S, VD9S and VD13S site-city models with the response of stand-alone structure in the same basin (CD1S model). Figure 15a clearly depicts the effect of surrounding structures on the response of the structure situated at the centre of VD3S 


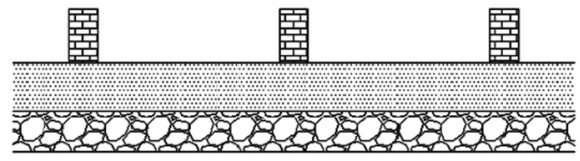

(a) VD3S

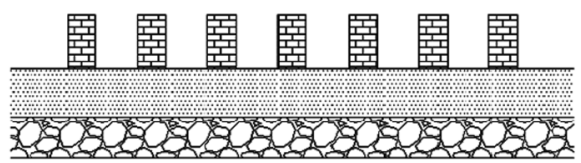

(c) VD7S

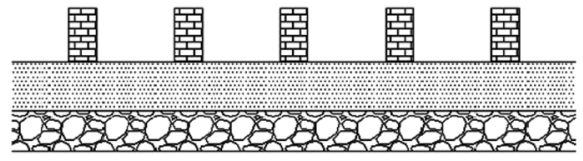

(b) VD5S

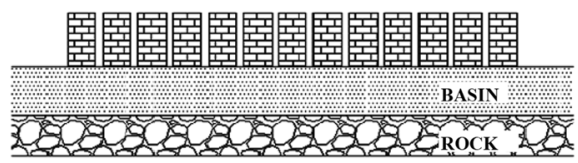

(d) VD135

Fig. 14 a-d The considered VD3S, VD5S, VD7S and VD13S site-city models with a constant span of city but with a variable city density

SCI model. There is an increase in ground-motion level due to constructive interference of diffracted waves generated by surrounding structures in the SH-wave response but not in the SV-wave response. However, with an increase in city density, the complex interaction of the diffracted waves by the structures with the basin is causing less ground-motion level at the top of the central structure of the VD5S, VD9S and VD13S site-city models in both the SH- and SV-wave responses. The beating phenomenon can also be seen very clearly in the SV-wave responses of the VD5S, VD9S and VD13S and to some extent SH-wave response of the VD13S site-city model.

\subsubsection{SH-wave response}

A comparison of the spectral amplifications of the SH-wave at the top of the structures situated at the centre of the VD3S, VD5S, VD9S and VD13S SCI models is shown in the left panel of Fig. 16a. The analysis of Fig. 16a reveals an increase in potential of reducing the SAF and to split the spectral bandwidth of $\mathrm{SH} F_{02 \mathrm{D}}^{\mathrm{BS}}$ of structure in city with the increase in city density. For example, the largest $\mathrm{SAF}$ at $\mathrm{SH} F_{02 \mathrm{D}}^{\mathrm{BS}}$ of central structure is $56.19,42.94,34.85$ and 22.40 in the VD3S, VD5S, VD9S and VD13S SCI models, respectively (Table 7). Furthermore, a trough is also occurring in the spectral amplification bandwidth of fundamental mode when the city density is high. The obtained ASA in the spectral bandwidth of fundamental mode as 7.03, 6.66, 6.24 and 5.42 in the case of the VD3S, VD5S, VD9S and VD13S SCI models, respectively, reflects the decrease in ASA with the increase in city density. Almost, similar effects in the spectral amplification bandwidth of first and higher modes of SH-wave can also be inferred.

A comparison of the left panel of Fig. 16a-e depicts that the largest $\mathrm{SAF}$ at $\mathrm{SF}_{02 \mathrm{D}}^{\mathrm{BS}}$ of a structure is highly variable with the city density and location in the city. For example, in the case of VD3S site-city model, the largest $\mathrm{SAF}$ at $\mathrm{SF}_{02 \mathrm{D}}^{\mathrm{BS}}$ of a structure is at the centre of the city and least at the edge of the city. This may be due to the constructive of the diffracted SH-waves from the edges building at the centre of city. In the case of VD13S site-city model, the obtained largest SAF in the bandwidth of fundamental mode of vibration of structure is continuously decreasing towards the centre of the city. On the other hand, in the case of VD7S site-city model, the obtained largest SAF in the bandwidth of fundamental mode of vibration of structure is decreasing up to a distance of $150 \mathrm{~m}$ and thereafter there is an increase at the centre of the city. However, a reduction in SAF and 

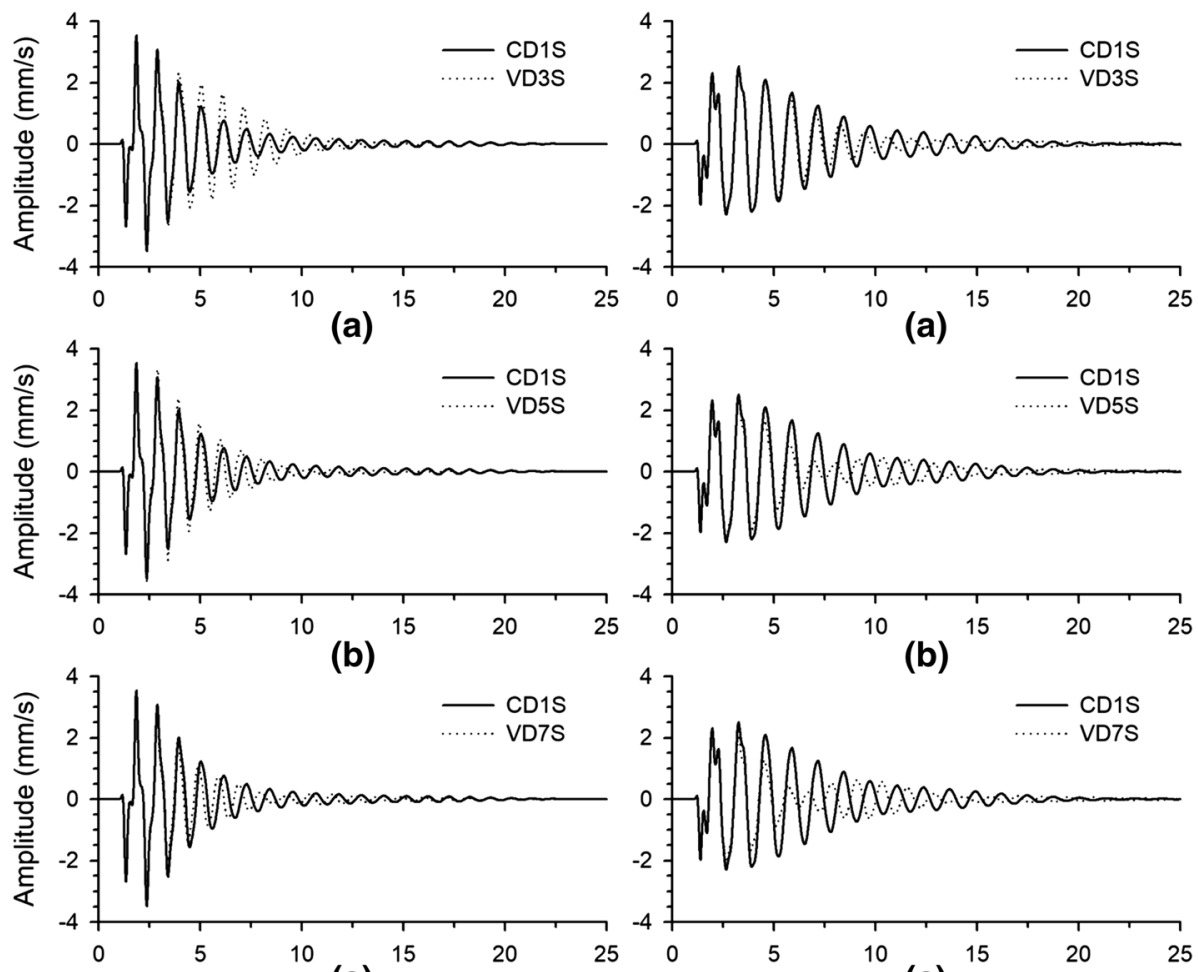

(b)

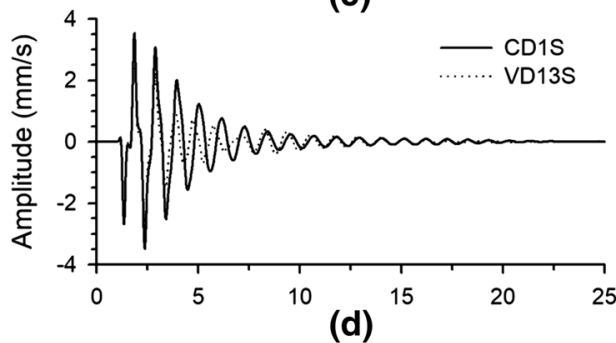

Time(s)

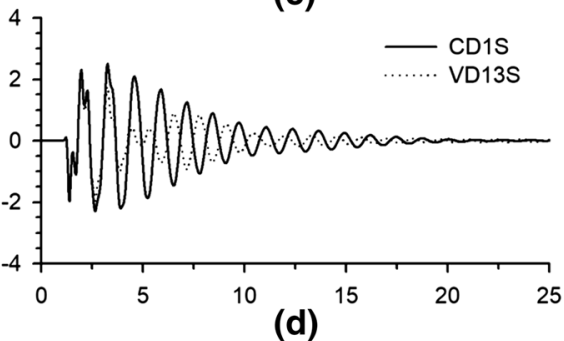

Time(s)

Fig. 15 a-d A comparison of SH-wave (left panel) and SV-wave (right panel) responses at the top of central structure of the VD3S, VD5S, VD7S and VD13S site-city models, respectively, with the response at the top of a stand-alone structure in the basin

splitting of the spectral bandwidth of the fundamental mode with the increase of city density can be inferred. The left panel of Fig. $16 \mathrm{f}$ depicts that there are no considerable effects of increase of city density on the frequency bandwidth corresponding to the fundamental frequency and corresponding SAF in the free-field motion outside the city. However, largest SAF is much lesser than that in the absence of city. The obtained ASA in the frequency bandwidth of fundamental mode of vibration of basin as 1.86, 1.87, 1.87 and 1.87 corresponding to the VD3S, VD5S, VD9S and VD13S SCI models, respectively, reflects that there is no considerable variation in the free-field motion due to the increase of city density, except largest SAF. 

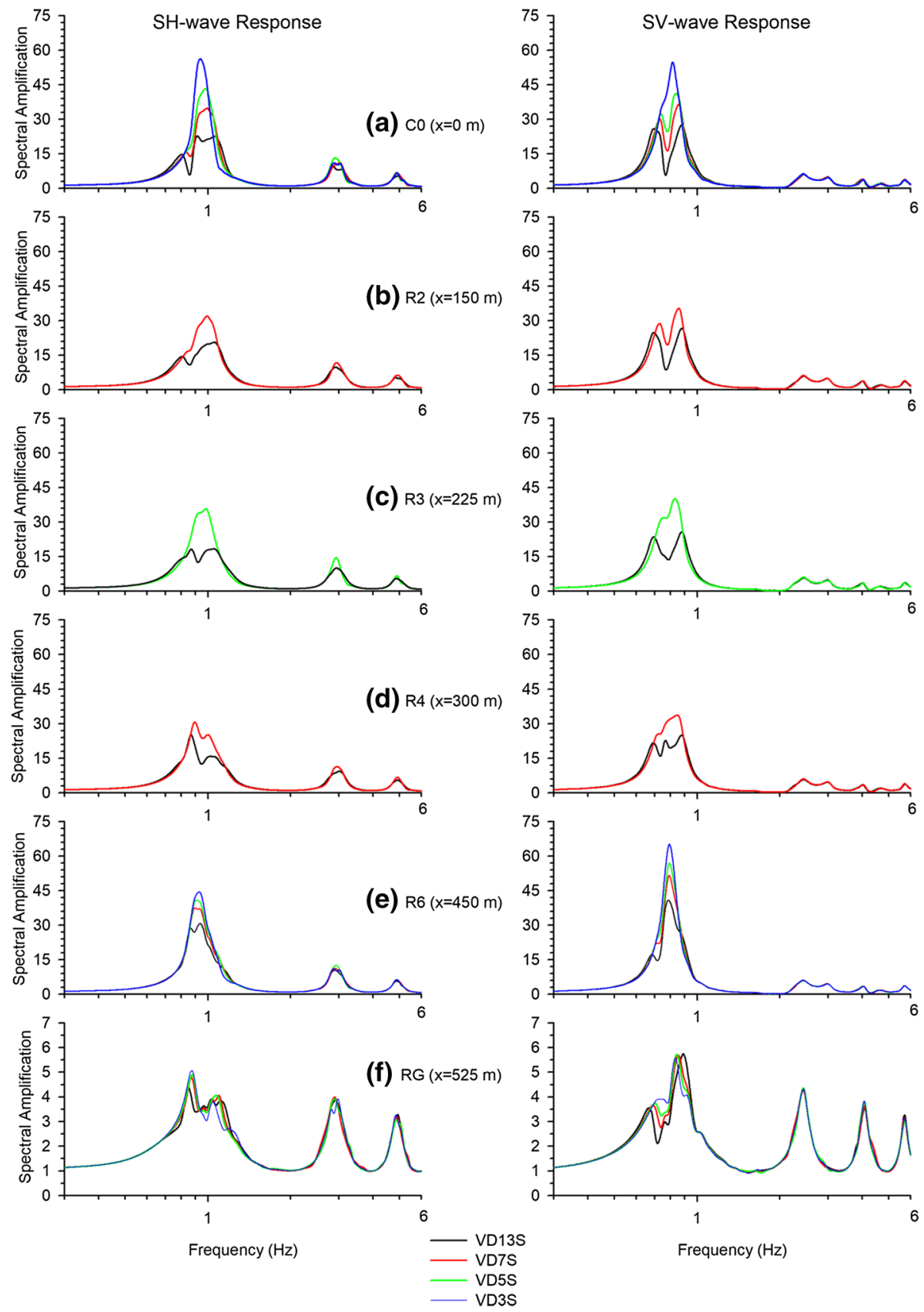

Fig. 16 a-e A comparison of spectral amplifications of the SH-wave (left panel) and SV-wave (right panel) at the top of the structures from the centre of various site-city models with a variable city density and $\mathbf{f}$ at the free surface in basin at a distance of $45 \mathrm{~m}$ from the left edge of the city 


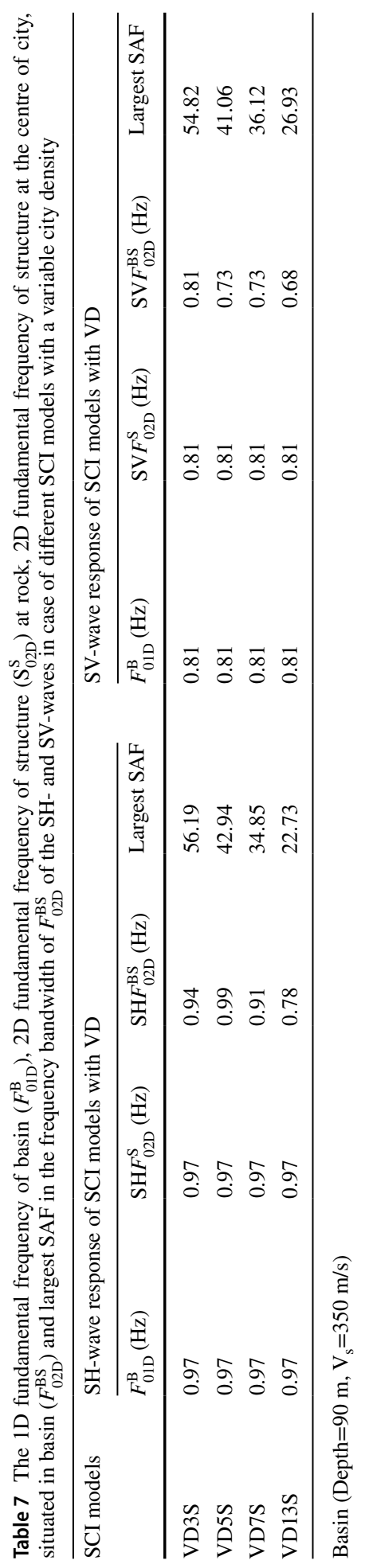




\subsubsection{SV-wave response}

A comparison of the spectral amplifications of the SV-wave at the top of the structure situated at the centre C0 $(x=0 \mathrm{~m})$ of VD3S, VD5S, VD9S and VD13S SCI models is shown in the right panel of Fig. 16a. Figure 16a clearly reveals an increase in potential of reducing the SAF and to split the spectral bandwidth of fundamental mode of vibration of structure with the increase in city density. For example, the frequency and SAF corresponding to the first spectral ratio peak are $0.81 \mathrm{~Hz}, 0.76 \mathrm{~Hz}, 0.73 \mathrm{~Hz}$ and $0.68 \mathrm{~Hz}$ and 54.82, 32.40, 29.35 and 25.45 in the VD3S, VD5S, VD9S and VD13S SCI models, respectively (Table 7). Furthermore, the value of spectral ratio trough in the spectral bandwidth of $S V F_{02 \mathrm{D}}^{\mathrm{BS}}$ is also decreasing with the increase in city density. Almost negligible effect of city density on the spectral amplifications at first and higher resonance modes can be inferred. A comparison of left and right panels of Fig. 16a, e reflects that the observed increase in $\mathrm{SAF}$ at $\mathrm{SH} F_{02 \mathrm{D}}^{\mathrm{BS}}$ at the top of structure situated in the centre of city is not observed at $\mathrm{SVF}_{02 \mathrm{D}}^{\mathrm{BS}}$ in the case of SV-wave response of VD3D site-city model. The SCI effects on the reduction in SAF and splitting of the spectral bandwidth of the fundamental mode with the increase of city density can be inferred in all the cases, and these effects are increasing towards the centre of the city. The right panel of Fig. $16 \mathrm{f}$ depicts that there are no considerable effects of increase in city density on the frequency bandwidth corresponding to the fundamental frequency and corresponding SAF in the free-field motion outside the city. However, largest SAF is much lesser than that in the absence of city, as was observed in the case of SH-wave responses. A comparison of Figs. 13 and 16 reveals that the number of spectral ratio ups and downs is more and does not occur at a well-defined frequency in the case of SV-wave responses of the structures as compared to the $\mathrm{SH}$-wave.

\section{Discussion}

The analysis of SH-wave and SV-wave responses of the 2D rectangular basin models with a large shape ratio (parameters and shape ratio as that of structures) revealed that there is an excellent correlation between the numerically computed fundamental frequency of basin for the $\mathrm{SH}$-wave $\left(\mathrm{SH}_{02 \mathrm{D}}^{\mathrm{B}}\right)$ and the $\mathrm{SV}$-wave $\left(\mathrm{SVF}_{02 \mathrm{D}}^{\mathrm{B}}\right)$ with the same computed using the respective empirical relations given by Bard and Bouchon (1985). Further, due to the lack of an empirical relation to predict the 2D fundamental frequency of structures for the $\mathrm{SH}$-wave $\left(\mathrm{SH}_{02 \mathrm{D}}^{\mathrm{S}}\right)$ and the $\mathrm{SV}$-wave $\left(\mathrm{SVF}_{02 \mathrm{D}}^{\mathrm{S}}\right)$, the above-mentioned excellent correlation gives a certificate to the accuracy of the computed $F_{02 \mathrm{D}}^{\mathrm{S}}$ of the structures. This certificate gets further support since the seismic parameters and the range of shape ratio of the structures are same as that of the analysed basins. It is interesting to note that $\mathrm{SH} F_{02 \mathrm{D}}^{\mathrm{S}}$ of the stand-alone structure on the rock and the $\mathrm{SAF}$ at $\mathrm{SH} F_{02 \mathrm{D}}^{\mathrm{S}}$ is not affected by the shape ratio of the structure. On the other hand, there is a drastic increase in reduction of $S V F_{02 \mathrm{D}}^{\mathrm{S}}$ of the stand-alone structure on the rock for SV-wave with an increase in shape ratio of the structure as compared to $F_{01 \mathrm{D}}^{\mathrm{S}}$ of structure with the shape ratio. For example, $19 \%$ reduction in $\mathrm{SV} F_{02 \mathrm{D}}^{\mathrm{S}}$ of structure as compared to $\mathrm{SV} F_{01 \mathrm{D}}^{\mathrm{S}}$ was obtained when shape ratio was 0.47 .

A splitting of bandwidth of fundamental mode of vibration of structure as well as very large reduction in $\mathrm{SAF}$ at $F_{02 \mathrm{D}}^{\mathrm{BS}}$ (reduced to around $40 \%$ as compared to standalone structure in basin) is obtained due to the SCI effects on the response of structure under double resonance condition in both the cases of SH- and SV-waves. Further, the 
splitting and reduction in $\mathrm{SAF}$ at $F_{02 \mathrm{D}}^{\mathrm{BS}}$ increase with an increase in city density and number of structures with a constant city density. Furthermore, the obtained trough in the bandwidth of fundamental mode of vibration of structure reflects that under special condition there may be unexpected response of the structure, means no damage even at double resonance condition. Kitada et al. (1999) also reported that SCI effects can considerably change the dynamic response of structures of a city, particularly the splitting or shifting of the fundamental mode frequency as compared to that of a stand-alone structure in basin. Bard et al. (2008) also confirmed the splitting of bandwidth of fundamental mode of vibration of a stand-alone structure in basin based on centrifuge tests and numerical modelling (Gueguen 2008; Laurenzano et al. 2010; Gueguen and Colombi 2016). The inferred splitting and associated vary large reduction in SAF at the fundamental frequency raise the question concerning the validity of ground-motion prediction using soil-structure interaction for the design of structures in an urban environment.

\section{Conclusions}

The analysis of simulated responses of rectangular basin and building block models situated on rock revealed an increase in fundamental frequency of basin $\left(F_{02 \mathrm{D}}^{\mathrm{B}}\right)$ with an increase in shape ratio for both the SH- and SV-waves (Bard and Bouchon 1985). Further, this increase in $F_{02 \mathrm{D}}^{\mathrm{B}}$ of basin with shape ratio was larger in the case of SV-wave. In contrast to this, a drastic decrease in fundamental frequency of structure for the SV-wave $\left(\mathrm{SVF}_{02 \mathrm{D}}^{\mathrm{S}}\right)$ with an increase in shape ratio was obtained. However, the fundamental frequency of structure for the $\mathrm{SH}$-wave $\left(\mathrm{SH}_{02 \mathrm{D}}^{\mathrm{S}}\right)$ was almost unaffected by the shape ratio and is more or less equal to the $\mathrm{SH} F_{01 \mathrm{D}}^{\mathrm{S}}$. The $\mathrm{SAF}$ at fundamental frequency was larger in the case of SV-wave in both the basin and stand-alone structure on rock as compared to that in the case of $\mathrm{SH}$-wave. In case of a stand-alone structure in basin, a considerable reduction in the value of $F_{02 \mathrm{D}}^{\mathrm{BS}}$ and only minor reduction in the value of $\mathrm{SV} F_{02 \mathrm{D}}^{\mathrm{BS}}$ were observed. Further, the SAF at SV $F_{02 \mathrm{D}}^{\mathrm{BS}}(69.3)$ was larger than that at $\mathrm{SH} F_{02 \mathrm{D}}^{\mathrm{BS}}(42.2)$ at the top of a stand-alone structure in 1D basin under double resonance condition.

A splitting of the bandwidth of fundamental mode of vibration of structure and a drastic decrease in SAF at $F_{02 \mathrm{D}}^{\mathrm{BS}}$ was obtained due to the SCI effects under double resonance condition. An increase in these effects with an increase of city density and the increase in structures in a city with a constant city density were obtained for both the cases of S-wave polarizations. These findings corroborate with the findings of Kitada et al. (1999), Bard et al. (2008) and Gueguen and Colombi (2016) and raise the question concerning the validity of ground-motion prediction using soil-structure interaction approach for the design of structures in an urban environment. The decrease in SAF at $F_{02 \mathrm{D}}^{\mathrm{BS}}$ of structure due to the SCI effect was larger in the case of SV-wave (reduced to 39\%) as compared to the SH-wave (reduced to 50\%). Further, the obtained spectral ratio trough (SAF reduced up to 10\%) in the bandwidth of fundamental frequency reflects that a particular structure may be surprisingly safe during an earthquake even under double resonance condition. The observed SCI effects were largest at the centre of the city and least at the outermost structure. Even at the outermost structure of the city, the SAF was lesser than that obtained in case of standalone structure in basin under double resonance condition. A considerable SCI effects on the free-field motion were observed in both the SH- and SV-wave responses. 
Open Access This article is distributed under the terms of the Creative Commons Attribution 4.0 International License (http://creativecommons.org/licenses/by/4.0/), which permits unrestricted use, distribution, and reproduction in any medium, provided you give appropriate credit to the original author(s) and the source, provide a link to the Creative Commons license, and indicate if changes were made.

\section{References}

Anderson JG (2004) Quantitative measure of the goodness-of-fit of synthetic seismograms. In: Proceedings of the 13th world conference on earthquake engineering (13WCEE), Vancouver, Canada, Paper 243

Bard PY, Bouchon M (1985) The two-dimensional resonance of sediment-filled valleys. Bull Seismol Soc Am 75(2):519-541

Bard PY, Chazelas JL, Guéguen P, Kham M, Semblat JF (2005) Site-city interaction. In: Oliveira CS, Roca A, Goula X (eds) Chapter 5 of the book "Assessing and managing earthquake risk (geo-scientific and engineering knowledge for earthquake risk mitigation: developments, tools and techniques)". Springer (new book series on Geotechnical, Geological and Earthquake Engineering). Hardcover. ISBN 1-4020-3524-1:91-114

Bard PY, Chazelas JL, Guéguen P, Kham M, Semblat JF (2008) Site-city-interaction. Assessing and managing earthquake risk. Springer, The Netherlands, pp 91-114

Chandra J, Guéguen P (2017) Nonlinear response of soil-structure systems using dynamic centrifuge experiments. J Earthq Eng. https://doi.org/10.1080/13632469.2017.1398692

Chavez-Garcia FJ, Cardenas-Soto M (2002) The contribution of the built environment to the free-field ground motion in Mexico City. Soil Dyn Earthq Eng 22:773-780

Cornou C, Gueguen P, Bard PY, Haghshenas E (2004) Ambient noise energy bursts observation and modeling: trapping of harmonic structure-soil induced-waves in a topmost sedimentary layer. J Seismol 8(4):507-524

Emmerich H, Korn M (1987) Incorporation of attenuation into time-domain computations of seismic wave fields. Geophysics 52:1252-1264

Gallipoli MR, Mucciarelli M, Castro RR, Monachesi G, Contri P (2004) Structure, soil-structure response and effects of damage based on observations of horizontal-to-vertical spectral ratios of microtremors. Soil Dyn Earthq Eng 24:487-495

Gueguen P (2008) Urban seismic ground motion: a coupled effect of site and urban environment. In: Proceedings of the 14th world conference on earthquake engineering (14WCEE), Beijing, China

Gueguen P, Bard PY (2005) Soil-structure and soil-structure-soil interaction: experimental evidence at the Volvi test site. J Earthq Eng 9(5):657-693

Gueguen P, Colombi A (2016) Experimental and numerical evidence of the clustering effect of structures on their response during an earthquake: a case study of three identical towers in the city of Grenoble, France. Bull Seismol Soc Am. https://doi.org/10.1785/0120160057

Gueguen P, Bard PY, Oliveira CS (2000) Experimental and numerical analysis of soil motion caused by free vibration of a building model. Bull Seismol Soc Am 90:1464-1479

Guéguen P, Bard P-Y, Chavez-Garcia FJ (2002) Site-city interaction in Mexico City-like environments: an analytical study. Bull Seismol Soc Am 92(2):794-811

Housner GW (1954) Effect of foundation compliance on earthquake stresses in multi-story buildings. Bull Seism Soc Am 44:551-569

IS-1893 (Part 1) (2002) Criteria for earthquake resistant design of structures-Part 1: general provision and buildings. Bureau of Indian Standards

Israeli M, Orszag SA (1981) Approximation of radiation boundary conditions. J Comput Phys 41:115-135

Jennings PC (1970) Distant motion from a building vibration test. Bull Seismol Soc Am 60:2037-2043

Kanamori H, Mori J, Anderson DL, Heaton TH (1991) Seismic excitation by the space shuttle Columbia. Nature 349:781-782

Kham M, Semblat JF, Bard PY, Dangla P (2006) Seismic site-city interaction: main governing phenomena through simplified numerical models. Bull Seismol Soc Am 96:1934-1951

Kim WY, Sykes LR, Armitage JH, Xie JK, Jacob KH, Richards PG, West M, Waldhauser F, Armbruster J, Seeber L, Dw WX, Lerner-Lam A (2001) Seismic waves generated by aircraft impacts and building collapses at World Trade Center, New York City. EOS 82(47):565-570

Kitada Y, Kinoshita M, Iguchi M, Fukuwa N (1999) Soil-structure interaction effect on an Npp reactor building. Activities of Nupec: achievements and the current status. In: Celebi M, Okawa I (eds) Proceedings of the UJNR workshop on soil-structure interaction, Menlo Park, California, 22-23 September, paper no. 18 
Kristeck J, Moczo P (2003) Seismic wave propagation in viscoelastic media with material disconuties- a 3 D 4th order staggered grid finite difference modeling. Bull Seismol Soc Am 93:2273-2280

Kumar N, Narayan JP (2018) Quantification of site-city-interaction effects on the response of structure under double resonance condition. Geophys J Int 212(1):422-441

Laurenzano G, Priolo E, Gallipoli MR, Mucciarelli M, Ponzo FC (2010) Effect of vibrating buildings on free-field motion and on adjacent structures: the Bonefro (Italy) case history. Bull Seismol Soc Am 100(2):802-818

Meza-Fajardo KC, Semblat JF, Chaillat S, Lenti L (2016) Seismic-wave amplification in 3D alluvial basins: 3D/1D amplification ratios from fast multipole BEM Simulations. Bull Seismol Soc Am 106(3):1267-1281

Moczo P, Kristek J, Vavrycuk V, Archuleta RJ, Halada L (2002) 3D heterogeneous staggered-grid finite-difference modelling of seismic motion with volume harmonic and arithmetic averaging of elastic moduli and densities. Bull Seismol Soc Am 92:3042-3066

Narayan JP, Kumar V (2013) A fourth-order accurate finite-difference program for the simulation of SHwave propagation in heterogeneous viscoelastic médium. Geofizika 30:173-189

Narayan JP, Kumar V (2014) P-SV wave time-domain finite-difference algorithm with realistic damping and a combined study of effects of sediment rheology and basement focusing. Acta Geophys 62(3):1214-1245

Narayan JP, Sahar D (2014) 3D viscoelastic finite-difference code and modelling of basement focusing effects on ground motion characteristics. Comput Geosci 18:1023-1047

Paolucci R (1999) Shear resonance frequencies of alluvial valleys by Rayleigh's method. Earthq. Spectra 15(3):503-521

Roten D, Fah D, Cornou C, Giardini D (2006) Two-dimensional resonances in Alpine valleys identified from ambient vibration wavefields. Geophys J Int 165:889-905

Sahar D, Narayan JP (2016) Quantification of modification of ground motion due to urbanization in a 3D basin using viscoelastic finite-difference modelling. Nat Hazards 81(2):779-806

Sahar D, Narayan JP, Kumar N (2015) Study of role of basin shape in the site-city interaction effects on the ground motion characteristics. Nat Hazards 75:1167-1186

Semblat JF, Kham M, Bard PY (2008) Seismic-wave propagation in alluvial basins and influence of sitecity interaction. Bull Seismol Soc Am 98:2665-2678

Stewart JP, Seed RB, Fenves GL (1999) Seismic soil-structure interaction in buildings, II: empirical findings. J Geotech Geoenviron Eng 125:38-48

Wirgin A (1995) Resonant response of a soft semi-circular cylindrical to an SH seismic wave. Bull Seismol Soc Am 85(1):285-299

Wirgin A, Bard PY (1996) Effects of building on the duration and amplitude of ground motion in Mexico City. Bull Seismol Soc Am 86:914-920

Wong HL, Trifunac MD (1975) Two dimensional antiplane building-soil-building interaction for two or more buildings and for incident plane SH waves. Bull Seismol Soc Am 65:1863-1885

Zeng C, Xia J, Miller R, Tsoflias G (2012) An improved vacuum formulation for 2D finite-difference modeling of Rayleigh waves including surface topography and internal discontinuities. Geophysics 77:T1-T9

Zhu C, Thambiratnam D (2016) Interaction of geometry and mechanical property of trapezoidal sedimentary basins with incident SH waves. Bull Earthquake Eng. https://doi.org/10.1007/s10518-016-9938-z

Publisher's Note Springer Nature remains neutral with regard to jurisdictional claims in published maps and institutional affiliations. 